\title{
BARRIO EL PRADO \\ un Museo Vivo para la Ciudad de Barranquilla.
}

Padilla-Llano, Samuel E. ; Machado-Penso, María V. ; Reyes-Schade, Emilio; Larios-Giraldo, Paola M.; Cabrera-Sánchez, Irina; Martínez-Palacios, Emerson; González-Forero, Daniel; Tapias-Martínez, Juan.

Universidad de la Costa. Departamento de Arquitectura y Diseño. Barranquilla-Colombia

reference e-mail: samuel@padillano.com

Recibido 19/03/2020 Evaluado 12/04/2020 Publicado 30/04/2020

\section{RESUMEN}

Barranquilla, ciudad ubicada en una latitud geográfica intertropical en el margen izquierdo de la desembocadura del Río Magdalena, se constituye como un conglomerado de trozos debido a sus procesos de urbanización. Procesos que inician un desarrollo urbano acelerado durante las primeras décadas del siglo XX, sin contar con un Plan Urbanístico para la ordenación de su vasto territorio. En ausencia de ello, se trazan, por un lado, barrios burgueses para alojar las migraciones europeas y por el otro, gracias a ese desarrollo, aparecen de manera espontánea, los barrios informales consolidados debido a la migraciones locales y regionales.

Entre los barrios burgueses se distingue el Barrio El Prado, desarrollado a partir de los principios urbanísticos del Movimiento Moderno, siguiendo el modelo de Ciudad Jardín, constituyéndose de esta manera, como el principal hito urbano de la ciudad en siglo XX. Es así como el Prado se caracterizó por la continuidad de su trazado y por erigir sobre cada uno de sus terrenos, edificaciones de estilos arquitectónicos equiparables a las que se construían en ciudades norteamericanas e inglesas de la época. Entre estas edificaciones, hoy patrimoniales se destacan la construcción de cincuenta y cuatro viviendas aisladas para la élite de Barranquilla, el Hotel El Prado y la puesta en funcionamiento del Country club.

El transcurrir del tiempo ha generado en el Barrio El Prado transformaciones funcionales que fueron modificando sus símbolos e imaginarios. Sin embargo, su declaratoria como Bien de Interés Cultural de carácter Nacional, a través de la Resolución 0087 el 2 de febrero de 2005, ha impedido la modificación estructural de sus piezas arquitectónicas patrimoniales, antejardines, patios y la mayoría de las especies vegetales, así como tampoco el trazado urbano. Actualmente en el barrio se vive una confluencia de manifestaciones integradas y complementarias, partiendo de aquellas propias del uso residencial en el Caribe, conjugadas con el desarrollo de actividades culturales en el espacio público, las cuales se articulan con escenarios culturales y artísticos que, con el tiempo se han establecido en el barrio. Esta confluencia ha generado una sinergia entre el modelo de Ciudad Jardín, la cotidianidad residencial propia del Caribe que habita parte del patrimonio arquitectónico, la cultura alojada en edificios patrimoniales y sus amplios espacios públicos, reafirmando lo vivo como una condición a considerar desde un patrimonio comprendido como cuestión de futuro. Una comprensión que, también pone en valor las manifestaciones humanas poco reconocidas, ya que con ello el territorio adquiere otros potenciales. Es así como la iniciativa del Museo Vivo El Prado potencia este 
valor como proceso de regeneración urbana.

El potencial valor de lo vivo, estructurado bajo el concepto de Museo, mediante el proceso de regeneración urbana, comprende al Barrio El Prado como un territorio de oportunidades clave en la gestión cultural y de innovación, mediante la puesta en marcha de otros modelos económicos, que excluyan la posibilidad de gentrificación. De esta manera esta investigación se sumerge en una profundización sobre estudios de regeneración urbana, la comprensión de la imagen de la ciudad como obra de arte y la investigación sobre la significación de museo en distintas instancias. Concretando de esta forma, la concepción de Museo Vivo como la definición de espacio urbano que, en primera instancia no saca su colección del contexto, sino que, por el contrario, genera la colección en torno a ella, tomando partida del sistema espacial, cultural dinámico, simbiótico, socialmente equilibrado, en el cual se desarrollan dinámicas democráticas y espontáneas que fundamentan y sustentan un sistema de equilibrios económicos, naturales y culturales. No se trata de crear un medio inerte intocable, sino de permitir acciones y relaciones entre visitantes y habitantes que potencien esas dinámicas.

Es así como El Museo Vivo El Prado, propuesto como un distrito de innovación cultural y creativo, no solo generará impacto y retribución económica, sino que posibilitará la transformación de imaginarios colectivos, fundamentando sus identidades y consolidando su imagen. Lo cual se verá favorecido por su planificación urbana inicial y dinamizadas por las formas de habitar que discurren en este entorno patrimonial, pudiéndose reconocer como una "marca propia", desde el marketing territorial en cuanto a su reconocimiento y promoción dentro de la ciudad a partir del fomento de la economía naranja, la cual es una de las metas del Gobierno Nacional Colombiano.

De este modo el Museo Vivo El Prado, se proyecta a partir de la comprensión del patrimonio como una cuestión de futuro, separándose de la concepción tradicional de museo, esto es, una concepción estática, inerte, inanimada, que saca la colección de su contexto y que utiliza los edificios como soportes para otras artes. Por el contrario, el Museo Vivo El Prado Ubica el concepto de museo en la dimensión de la gestión y regeneración urbana conjugada con procesos de economía creativa, para ser entregadas a un espacio democrático, de uso público, libre y al aire libre. Es así como el espacio urbano es el propio museo, sus límites, el territorio sobre el cual se posa el patrimonio administrativamente definido y el cielo como su confín superior.

PALABRAS CLAVE: Museo; Identidad urbana; Imagen de ciudad; Patrimonio; Arte Público; Espacio Público.

\section{ABSTRACT}

Barranquilla, a city located in an intertropical geographical latitude on the left bank of the Magdalena's River mouth, is constituted as a conglomerate of pieces due to its urbanization processes. Processes that began an accelerated urban development during the first decades of the 20th century, without an Urban Plan for the management of its vast territory. In the absence of this, bourgeois neighborhoods are drawn up to allocate European Immigrants by the time that other informal neighborhoods appear spontaneously to allocate local and regional immigrants.

Among the bourgeois neighborhoods, El Prado neighborhood stands out, developed according to the urbanistic principles of the Modern Movement, following the Garden City model, it constitutes the main urban landmark of the city in the 20th century. That is how El Prado is planned with a continuous urban layout and built in each of its properties, houses, and buildings of architectural styles like those built in the north American and British cities. Among these buildings, which are now patrimonial, stands out: the construction of fifty-four isolated houses for the Barranquilla elite, the El Prado Hotel and the opening of the Country Club.

The passing of time has generated functional transformations in the El Prado neighborhood that have modified its symbols and imaginaries. However, the declaration as an Asset of National Cultural Interest, through Resolution 0087 on February 2, 2005, has prevented the structural modification of its architectural heritage pieces, front gardens, courtyards, and most of the plant species, as well as the urban layout. Nowadays there are a confluence of integrated and complementary manifestations that can be lived in the neighborhood and are conjugated with cultural activities developed in the urban space, activities that are linked with cultural and artistic scenarios which by the passing of the time have been set up in the neighborhood. This confluence has generated a synergy between the Garden City model, the typical daily residential life of the Caribbean that inhabits part of the architectural heritage, the culture hosted in heritage buildings and the wide open public spaces, reaffirming the living as a condition to be considered from the heritage understanding as a matter of future. An understanding that, also puts in value the human manifestations that are less recognized, since with it, the territory acquires other potentials. This is how the initiative of the Museo Vivo El Prado promotes this value as a process of urban regeneration. 
The potential value of the living, structured under the concept of Museum, through the process of urban regeneration, includes the El Prado neighborhood as a territory of key opportunities in cultural management and innovation, through the startup of other economic models that exclude the possibility of gentrification. That is how this research is immersed to an in-depth study of urban regeneration, the understanding of the image of the city as a piece of art and the research on the significance of museums in different instances. Concretizing this way, the conception of the Living Museum as the meaning of urban space that firstly, does not take its collection out of context, but in opposition, is generated around itself, taking advantage of the dynamic, symbiotic, socially balanced spatial and cultural systems in which democratic and spontaneous dynamics that develop, grounds and support an economic, natural and cultural equilibrated system. It is not a matter of creating an untouchable inert environment, but to allowing actions and relationships between visitors and inhabitants that enhance those dynamics.

This is how The Museo Vivo El Prado, proposed as a cultural and creative innovation district, will not only generate impact and economic retribution, but it will also make possible the transformation of collective imaginaries, founding their identities and consolidating their image. That will be favored by its initial urban planning energized by the ways of living that happens in this heritage environment, letting it being recognized as its "own brand", from the territorial marketing, in terms of recognition and promotion within the city, by the incentive of the 'Orange economy' that is one of the Colombian National Government goals

In this way, the Museo Vivo El Prado is projected from the understanding of the heritage as a matter of future, standing apart from the traditional concept of a museum, this is, as a static, inert and inanimate concept that takes out the collection of its context and uses the buildings as a supports for other artwork. In Opposition the Museo vivo El Prado places the concept of the museum in the dimension of urban management and regeneration combined with creative economy processes, to be handed over to a democratic, public, open-air space. That is how the urban space is the museum itself, its limits are the territory on which the heritage is administratively placed and the sky as its upper border.

KEY WORDS: Museum; Urban Identity; City's Image; Heritage; Public Art; Public Space

\section{RESUM}

Barranquilla, ciutat situada a una latitud geogràfica intertropical al marge esquerre de la desembocadura de el Riu Magdalena, es constitueix com un conglomerat de trossos a causa dels seus processos d'urbanització. Processos que inicien un desenvolupament urbà accelerat durant les primeres dècades de segle XX, sense comptar amb un Pla Urbanístic per a l'ordenació del seu vast territori. En absència d'això, es tracen, d'una banda, barris burgesos per allotjar les migracions europees i de l'altra, gràcies a aquest desenvolupament, apareixen de manera espontània, els barris informals consolidats a causa de la migracions locals i regionals.

Entre els barris burgesos es distingeix el Barri El Prat, desenvolupat a partir dels principis urbanístics de el Moviment Modern, seguint el model de Ciutat Jardí, constituint-se d'aquesta manera, com el principal fita urbana de la ciutat en segle XX. És així com el Prat es va caracteritzar per la continuïtat del seu traçat i per erigir sobre cadascun dels seus terrenys, edificacions d'estils arquitectònics equiparables a les que es construïen en ciutats nord-americanes i angleses de l'època. Entre aquestes edificacions, avui patrimonials es destaquen la construcció de cinquanta-quatre habitatges aïllats per a l'elit de Barranquilla, l'Hotel El Prado i la posada en funcionament del Country club.

El transcórrer de el temps ha generat en el Barri El Prat transformacions funcionals que van ser modificant els seus símbols i imaginaris. No obstant això, la seva declaratòria com a Bé d’Interès Cultural de caràcter Nacional, a través de la Resolució 0087 el 2 de febrer de 2005, ha impedit la modificació estructural de les seves peces arquitectòniques patrimonials, antejardins, patis i la majoria de les espècies vegetals, així com tampoc el traçat urbà. Actualment al barri es viu una confluència de manifestacions integrades i complementàries, partint d'aquelles pròpies de l'ús residencial al Carib, conjugades amb el desenvolupament d'activitats culturals a l'espai públic, les quals s'articulen amb escenaris culturals i artístics que, amb el temps s'han establert al barri. Aquesta confluència ha generat una sinergia entre el model de Ciutat Jardí, la quotidianitat residencial pròpia de l'Carib que habita part de el patrimoni arquitectònic, la cultura allotjada en edificis patrimonials i els seus amplis espais públics, reafirmant el viu com una condició a considerar des d'un patrimoni comprès com a qüestió de futur. Una comprensió que, també posa en valor les manifestacions humanes poc reconegudes, ja que amb això el territori adquireix altres potencials. És així com la iniciativa del Museu Viu El Prat potencia aquest valor com a procés de regeneració urbana.

El potencial valor del que viu, estructurat sota el concepte de Museu, mitjançant el procés de regeneració urbana, comprèn a el Barri El Prat com un territori d'oportunitats clau en la gestió cultural i d'innovació, mitjançant la posada 
en marxa d'altres models econòmics, que excloguin la possibilitat de gentrificació. D’aquesta manera aquesta investigació es submergeix en un aprofundiment sobre estudis de regeneració urbana, la comprensió de la imatge de la ciutat com a obra d'art i la investigació sobre la significació de museu en diferents instàncies. Concretant d'aquesta manera, la concepció de Museu Viu com la definició d'espai urbà que, en primera instància no treu la seva col·lecció de l'context, sinó que, per contra, genera la col·lecció entorn d'ella, prenent partida de sistema espacial, cultural dinàmic, simbiòtic, socialment equilibrat, en el qual es desenvolupen dinàmiques democràtiques i espontànies que fonamenten i sustenten un sistema d'equilibris econòmics, naturals i culturals. No es tracta de crear un mitjà inert intocable, sinó de permetre accions i relacions entre visitants i habitants que potenciïn aquestes dinàmiques.

És així com El Museu Viu El Prat, proposat com un districte d'innovació cultural i creatiu, no només generarà impacte i retribució econòmica, sinó que possibilitarà la transformació d'imaginaris col·lectius, fonamentant les seves identitats i consolidant la seva imatge. La qual cosa es veurà afavorit per la seva planificació urbana inicial i dinamitzades per les formes d'habitar que discorren en aquest entorn patrimonial, podent-se reconèixer com una "marca pròpia", des del màrqueting territorial pel que fa al seu reconeixement i promoció dins de la ciutat a partir del foment de l'economia taronja, la qual és una de les metes de Govern Nacional Colombià.

D’aquesta manera el Museu Viu El Prat, es projecta a partir de la comprensió de el patrimoni com una qüestió de futur, separant-se de la concepció tradicional de museu, és a dir, una concepció estàtica, inert, inanimada, que treu la col-lecció del seu context i que utilitza els edificis com a suports per a altres arts. Per contra, el Museu Viu El Prat Situa el concepte de museu en la dimensió de la gestió i regeneració urbana conjugada amb processos d’economia creativa, per a ser lliurades a un espai democràtic, d'ús públic, lliure i a l'aire lliure. És així com l'espai urbà és el propi museu, els seus límits, el territori sobre el qual es posa el patrimoni administrativament definit i el cel com el seu confí superior.

PARAULES CLAU: Museu; Identitat urbana; Imatge de ciutat; patrimoni; Art Públic; Espai Públic

\section{LA IMAGEN DE LA CIUDAD: BARRANQUILLA}

La primera imagen que deviene a nuestras mentes al escuchar sobre las ciudades del Caribe es la de un paisaje natural caracterizado por el inmenso mar de aguas cristalinas que juegan con el efecto visual multicolor en tonos azulados, verdes y grises, satinados por un sol radiante que es envidiable en las latitudes en que el "astro rey" sólo se avista en pocas horas del día y que es activo en épocas específicas del año.

En ese imaginario de la ciudad caribe encontramos un sinnúmero de elementos que configuran el paisaje urbano de las ciudades. Encontramos, por ejemplo, la "palmera cocotera", esa planta arborescente icónica, que induce al descanso y al relax, como elemento iconográfico del caribe más entrañable, que evoca al Realismo Mágico "Garciamarquiano" y que lleva impregnada una localización geográfica especifica en el imaginario colectivo de cualquier persona en el mundo.

También asociamos la presencia de la arena blanca y gris, semejante a un manto creado por polvos de diamantes que se posan como un exclusivo tapete para dramatizar aún más la sensación de estar en un lugar de lujo y de privilegio. Un cielo que ofrece espectaculares tonos azules, rojizos y anaranjados al pasar las horas del día y se intensifica cuando empieza a caer la tarde, tal si se estuviera incendiando la tierra.

A lo que se suma, la idea de una gastronomía basada principalmente en el exquisito marisco, acompañado de refrescantes bebidas frutales exóticas, o por una jarra de cerveza "michelada". Y no menos importante, unas gentes que, con su particular identidad cultural, irradian autenticidad; 



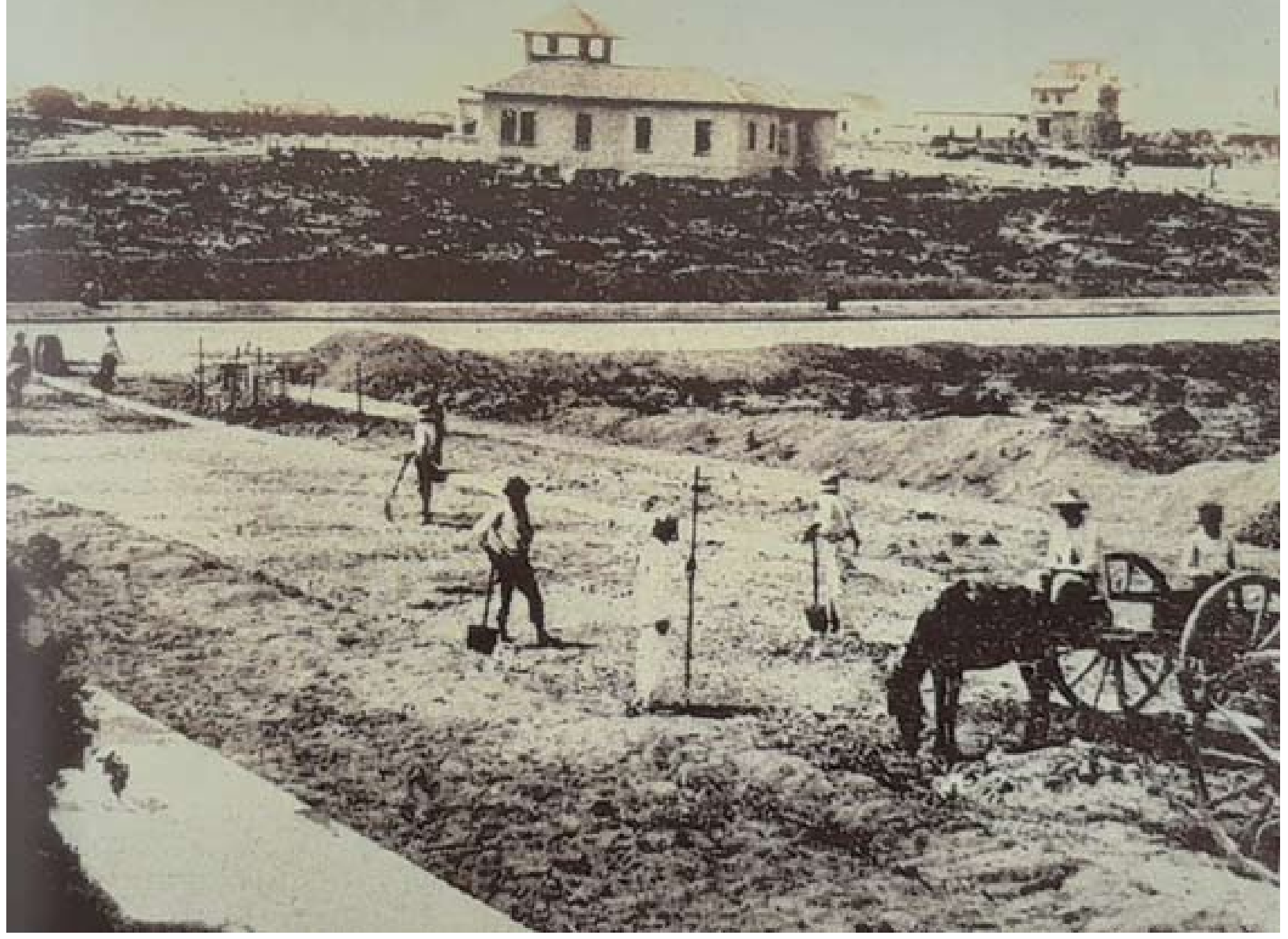

Imagen 2. Barrio EL Prado. Pavimentación de Avenida E. Fuente: Ferro-Bayona, J.; Llanos-Diaz R. (2016).

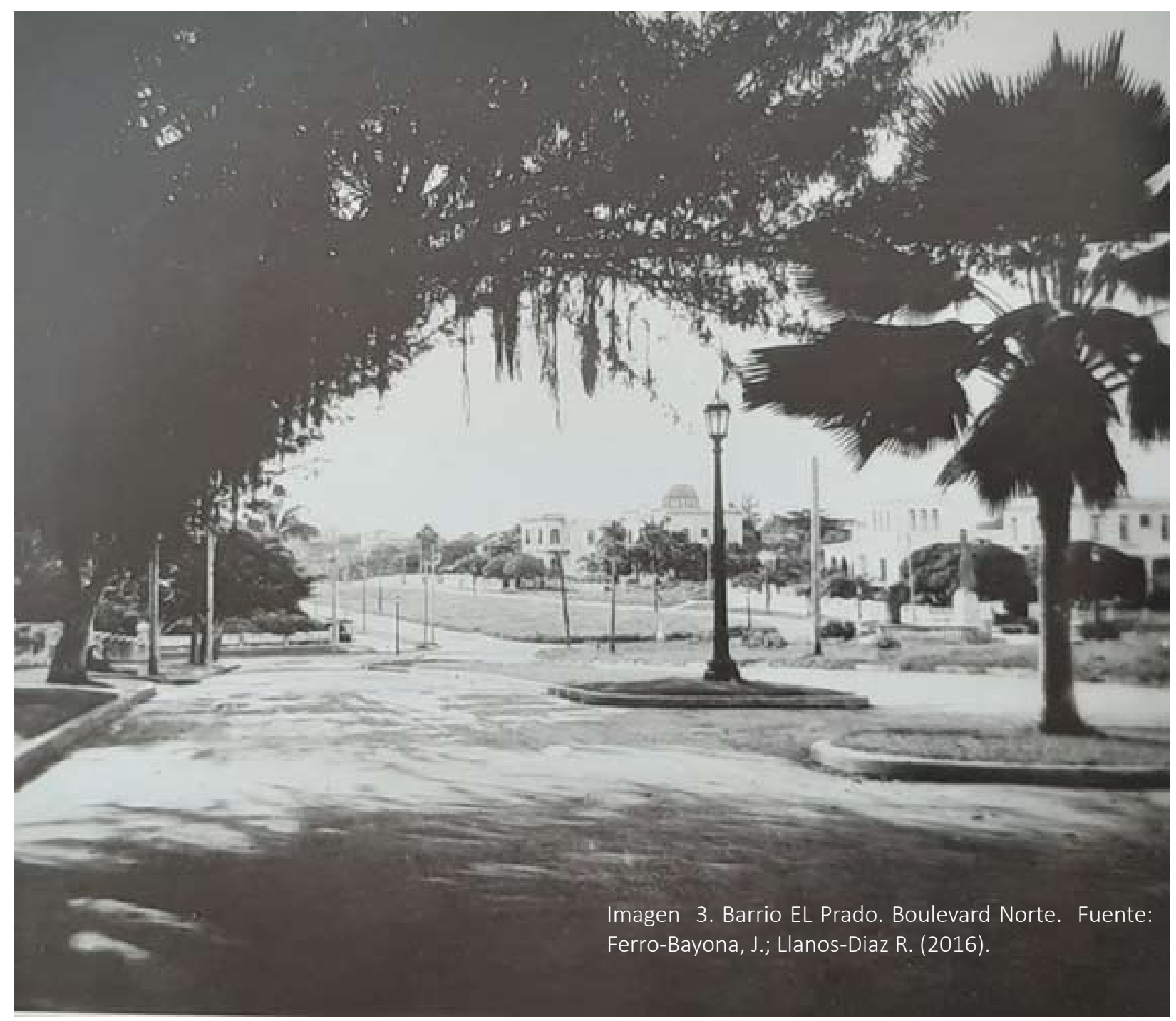


europeas (en el contexto de la Primera y Segunda Guerra Mundial), no solo importando elementos propios de la cultura de origen, sino también, los elementos claves para el desarrollo del país, como las industrias especializadas, la aviación y la movilidad, reflejando el deseo de modernidad propio de la época de la República (Pérgolis, 2011). Por el otro también aparecían los nuevos barrios informales que empezaban a consolidarse, gracias a las migraciones locales y regionales que encontraban en la Barranquilla de entonces, un territorio de oportunidades, instalándose, casi siempre en las periferias urbanas.

Estos Barrios burgueses (y principalmente El Barrio El Prado), comenzaron a desarrollarse con un trazado planificado como piezas singulares, dando origen a la planificación urbana moderna de la ciudad. Estos barrios no solo se caracterizaban por su morfología proporcional, sino que además su imagen estaba aderezada con los exquisitos movimientos estéticos y estilísticos de la arquitectura de principios de siglo en las ciudades norte americanas e inglesas. Todo esto en contraste y desarticulado a esos otros nuevos barrios que también iban progresivamente consolidando la ciudad, desde las periferias urbanas.

La metáfora de una "colcha de retazos urbanos" sería apropiada para definir la imagen de la ciudad de Barranquilla, una ciudad que ha crecido progresivamente, sin un plan general de urbanización, con una heterogeneidad de ordenes urbanos, pero que en gran medida debe su estructura y crecimiento al barrio El Prado, como uno de los primeros barrios residenciales que surgió en la ciudad basado en un diseño y planificación urbana, del cual, gracias a la continuidad de su trazado, se desprendió, en gran medida, la estructura que tiene actualmente la ciudad. ${ }^{1}$

Ahora bien, la génesis de la ciudad evidencia la idoneidad de su localización y las funciones que debería afrontar la nueva urbe con respecto a las necesidades que demandaban los pobladores de los asentamientos vecinos más cercanos. No eran otra cosa más, que buscar la forma de obtener inicialmente todos los recursos que el agua proporcionaba a los sistemas productivos arraigados de la época, para la ganadería y la agricultura; y posteriormente, alcanzando la posibilidad de distribuir y comercializar sus excedentes por vía fluvial con destino a las más alejadas posibles fuentes de consumo. Razones que fueron determinantes para su posterior consolidación logística e industrial.

No obstante, es importante entender que la historia del urbanismo en Barranquilla surge con el afán de su colectivo más influyente por forjar un paisaje urbano coherente y planificado a la altura de las posibilidades del habitante promedio de principios del siglo XX. Sin lugar a equívocos esta disciplina se empieza a plasmar con la materialización del barrio El Prado, ejemplo precoz para Latinoamérica, al contextualizar sutilmente al ámbito caribe, el reflejo del modelo de ciudad burguesa inspirada por los principios estéticos e higienistas que emergen tanto de la ciudad jardín europea, como de la reinterpretación de esta, que ensalza los suburbios americanos de finales del siglo XIX.

1.- La Urbanización del Barrio El Prado se inicia en 1920, sumándose a otros escenarios urbanos en la ciudad, repletos de señorío como el Camellón del Paseo Bolívar, así como a una serie de plazas con monumentos en el espacio público y tres barrios residenciales aproximadamente. 


\section{El Prado, un contexto.}

El Barrio El Prado es uno de los 73 barrios que actualmente posee la ciudad de Barranquilla, y uno de aquellos que emergieron a principios del Siglo XX en Latinoamérica bajo los postulados, ideales y criterios urbanísticos del Movimiento Moderno y del modelo de Ciudad Jardín (planteado por Ebenezer Howard en 1903). Un siglo que se caracterizó "por una exploración urbanística y especialmente arquitectónica, basada en los valores estéticos, formales y espaciales de la ciudad" (Padilla, 2015). Grandes bulevares alineados con hermosos y coloridos antejardines, con un paisajismo que monumentaliza las casas y edificaciones de un barrio que ha sido estructurante del desarrollo de Barranquilla que, como todo espacio moderno, "es medido cuidadosamente, logra gran simplicidad y al mismo tiempo dramatismo" (Cabas, 2010).

Aunque para los años 20 del siglo pasado, Barranquilla no contaba con un Plan Urbanístico equiparable a los icónicos históricos: Barcelona, París, New York o Londres, el barrio El Prado adquirió gran importancia dentro de la estructura de la ciudad y su organización, pues aparece como el principal hito urbanístico para la ciudad en el siglo XX.

El Barrio El Prado, debido a su origen en 1920 y durante su desarrollo como sector de residencia de la élite barranquillera, contaba en sus inicios con un carácter específico y actividades orientadas al quehacer cotidiano propio de las familias más prestantes de la ciudad y de las minorías cultas e intelectuales (Vergara y Vidal, 2009), en donde el uso del suelo predominante era el residencial ${ }^{2}$ y por ello sus dinámicas estaban vinculadas a la vida de barrio, a la actividad social, complementada con la construcción del Hotel El Prado, entre 1927 y 1930, y la puesta en funcionamiento del Country club en el año 1926, sumada a las prácticas deportivas en los campos de golf o en el club de tenis, y al departir entre vecinos en los generosos paseos, antejardines y bulevares, atributos característicos del barrio, que lo distinguían del resto de la naciente urbe, constituyéndose en ese entonces como la síntesis de las acciones modernizadoras y la cumbre en las manifestaciones del modernismo arquitectónico de la ciudad (Caballero, 2000).

Gracias a la continuidad de su trazado y la extensión de sus principales ejes viales se fueron desarrollando los nuevos núcleos urbanos y barrios de la ciudad. El prado se convertiría entonces en ese nuevo centro histórico de Barranquilla (paralelo al centro histórico tradicional) para una nueva burguesía que se empezaba a instalar en la ciudad. Un paradigma del desarrollo y la pujanza de un nuevo territorio que, en aquellos días, protagonizaba el desarrollo de toda la nación. Barranquilla fue pionera de la aviación, del transporte comercial Fluvial y de la industria ferroviaria del país; y el Barrio El prado, era en gran medida, protagonista de ello, pues las familias que lideraban, en aquellos años, ese desarrollo, en su mayoría tenían sus residencias en El Prado.

2.- Fueron limitados los usos de suelo originales en El Barrio, porque seguían al pie de la letra las disposiciones plasmadas en el Reglamento general para los solares y constructores en el área urbanizada, por Parrish \& Co, entre los que se prohibía la construcción de fábricas, pesebreras, hospitales, asilos, cuarteles, escuelas públicas, teatros y circos, galleras, mataderos, mercados, salones de bailes públicos, cantinas, clubes y garajes públicos, tal como reza en el Artículo 3 del mencionado reglamento. (Vergara, Vidal, 2009) 
Con el transcurrir de los años y al modificarse las dinámicas urbanas que trajeron consigo la expansión del territorio, se dieron cambios en los usos de suelo en El Prado y sobrevino el surgimiento de nuevos barrios aledaños, producto de la iniciativa de la misma Compañía constructora y con una estrategia similar: hacia el sur el barrio Boston, con destacadas influencias de la arquitectura de la época de la República, en similar uso de detalles, pero con edificaciones de menor escala debido a su destinación para uso de la clase media; hacia el oriente el barrio Bellavista a partir de 1927, un tranquilo sector residencial, con arquitectura propia de la época que en Colombia se conoce como Transición, comprendida entre los años 30 y 45 del siglo pasado (Arango, 1993), y caracterizada principalmente por edificaciones Art Deco, y, entre los años 1935 y 1944, el barrio Altos del Prado hacia el noroccidente, con los primeros ejemplares de la arquitectura del movimiento moderno en Colombia y con distinta morfología urbana. Esto motivó el traslado de algunos residentes a zonas más exclusivas y provocó la paulatina transformación del comportamiento y de los usos del barrio El Prado que, como organismo vivo, fue derivando en una natural resignificación de sus dinámicas originales.

Si bien todo este proceso urbanizador tiene soporte en la apuesta política acorde con la tradición de la ciudad hasta ese momento y consciente de los desequilibrios que se venían experimentando en materia de crecimiento urbano, la ciudad ya contenía núcleos urbanos desarticulados y muy distintos entre sí, que no daban una unidad urbana, contrario a los planteamientos urbanos de la época que desarrollaban las ciudades europeas y de los cuales las ciudades latinoamericanas empezaban a aprender. Barranquilla entonces (y quizá aún hoy) aparecía como la sumatoria de fragmentos urbanos (o como una "colcha de retazos urbanos") que necesitaba de una organización sistémica y una visión de futuro que regulara su crecimiento.

Con estos cambios de residentes, de necesidades y de preferencias en cuanto a vivienda para la élite y las consecuentes transformaciones funcionales del barrio, fueron modificándose también sus símbolos e imaginarios que aún en la actualidad, continúan en constante evolución.

Por fortuna en el año 2005, se inicia el control de las intervenciones arquitectónicas patrimoniales en los sectores Prado, Bellavista y una parte de Altos del Prado, gracias a la Resolución 0087 del 2 de febrero de 2005, en la que se les declara Bienes de Interés Cultural de carácter nacional. En la actualidad, se encuentra en proceso de aprobación el Plan Especial de Manejo y Protección (PEMP) para esta zona patrimonial, a través del cual quedarán establecidas las acciones que garanticen su conservación y sostenibilidad, así como la generación de estrategias para su puesta en valor y apropiación por parte de la comunidad.

Las imponentes edificaciones con amplios patios y antejardines, otrora domésticas, han ganado con el tiempo usos que van desde lo institucional y comercial hasta lo cultural, propiciando una dinámica más heterogénea, tanto de sus residentes tradicionales, como de los transeúntes regulares y de los usuarios de servicios y productos que en el barrio se ofrecen, cumpliendo con una de las características morfológicas representativas del 


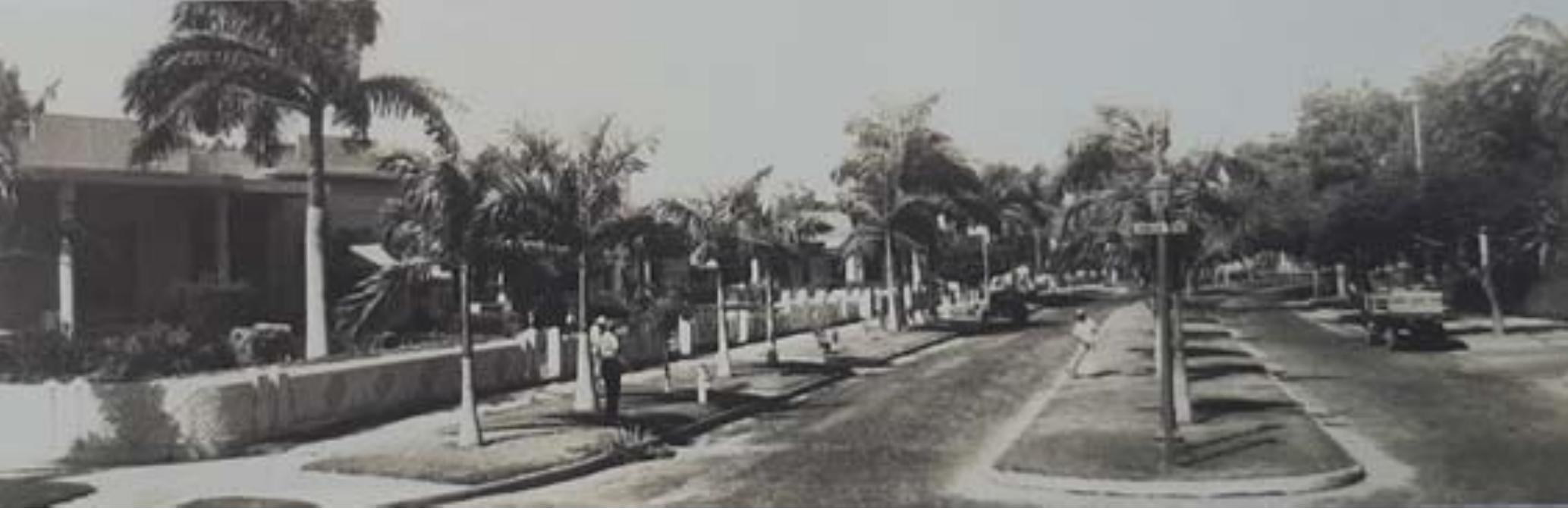

Imagen 4. Barrio EL Prado. Boulevard Sur.

Fuente: Ferro-Bayona, J.; Llanos-Diaz R. (2016).

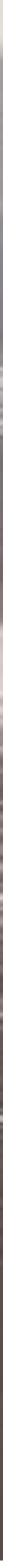

Imagen 5. Barrio EL Prado. Piscina del Hotel El Prado.

Fuente: Ferro-Bayona, J.; Llanos-Diaz R. (2016). 
crecimiento en los modelos de ciudad jardín o en ensanche, como lo es la flexibilidad en el tiempo y adaptabilidad a las necesidades cambiantes de los usuarios (Ferro y Llanos, 2016).

Actualmente en el barrio El Prado se vive una confluencia de manifestaciones integradas y complementarias, partiendo de aquellas propias del uso residencial en el Caribe, como el sentarse en la terraza a conversar con los vecinos al caer la tarde y realizar espontáneas tertulias en la frutera al salir de eventos religiosos, hasta el desarrollo de actividades colectivas en los espacios públicos de la zona, que actúan como extensión de la gran cantidad de escenarios culturales y artísticos que con el tiempo se han establecido en el barrio: desde museos, escuelas de bellas artes, galerías, anticuarios, academias de teatro e instituciones de diverso tipo, reafirmando la importancia de lo tradicional y lo vivo como factor diferenciador en El Prado ${ }^{3}$.

Allí se evidencia la amplitud de la dimensión patrimonial, en la que no sólo los valores estéticos o históricos son los únicos criterios de calificación del patrimonio. Entra a aportarle a estos valores macro, con una importancia fundamental, el aspecto simbólico, reflejado en las manifestaciones poco reconocidas y aquellas características representativas y originarias de esta segunda vida del barrio que también hacen parte de su Identidad, en las que el componente humano cobra singular relevancia, y el físico/territorial adquiere un nuevo potencial, que se activará mediante la Puesta en valor de la iniciativa de Museo Vivo El Prado como proceso de regeneración urbana. Tal como lo enuncia Giovanni De Piccoli (2017): "el patrimonio es (...) un recipiente de historia de las cuales muchas se pierden en el devenir del tiempo, otras, por el contrario, permanecen y se robustecen con el fin de preservarse, y otras adquieren nuevos matices que las actualizan".

Si vemos el barrio El Prado hoy, es claro identificarlo como un territorio de oportunidades, no sólo desde la revalorización del patrimonio, sino como elemento clave en la agenda de la gestión de la ciudad dentro de los nuevos modelos económicos basados en la cultura y la innovación. Además, es claro que para bien o para mal se han puesto los ojos en este, el quizá más importante de los Barrios Prado de Latinoamérica. Para bien, porque las industrias culturales, y un sector comercial han encontrado un plus mercantil en la revalorización y restauración de bienes patrimoniales para uso cultural, gastronómico o educativo, que mantienen vital y activo el territorio. Para mal, porque el mismo proceso de crecimiento y desarrollo de la ciudad y el coste de conservación de los bienes patrimoniales, han generado una cierta gentrificación, en la que aquel patrimonio intangible, que daba identidad a la vida barrial en El Prado, está amenaza ya que un gran porcentaje de sus antiguos propietarios han decidido irse a otros barrios, o a vivir fuera de la ciudad.En la actual disputa entre la decadencia del barrio y el deseo de un nuevo impulso de desarrollo económico, cualquier proceso de revitalización, gestión urbana para la preservación del barrio El Prado deberá estar centrado en la reivindicación de la imagen urbana y los grandes aportes estéticos y estilísticos del siglo pasado en la ciudad, enfocándolo no solo en el patrimonio arquitectónico y urbanístico,

3. De acuerdo a la investigación realizada por Emilio Yidi Daccarett y a Diana Meyer Vengoechea para el libro Barrio El Prado, un viaje hacia el pasado, y sustentado con bellísimas fotografías de archivos privados y postales de autores de la talla del reconocido fotógrafo italiano Floro Manco, se evidencia la gran cantidad de eventos de carnaval realizados en la segunda y tercera década del siglo pasado en el barrio, en la que se ilustra la primera Batalla de flores por los bulevares del Prado, los desfiles de coches, carrozas y de distintas comparsas. (Meyer, Yidi, 2015). 


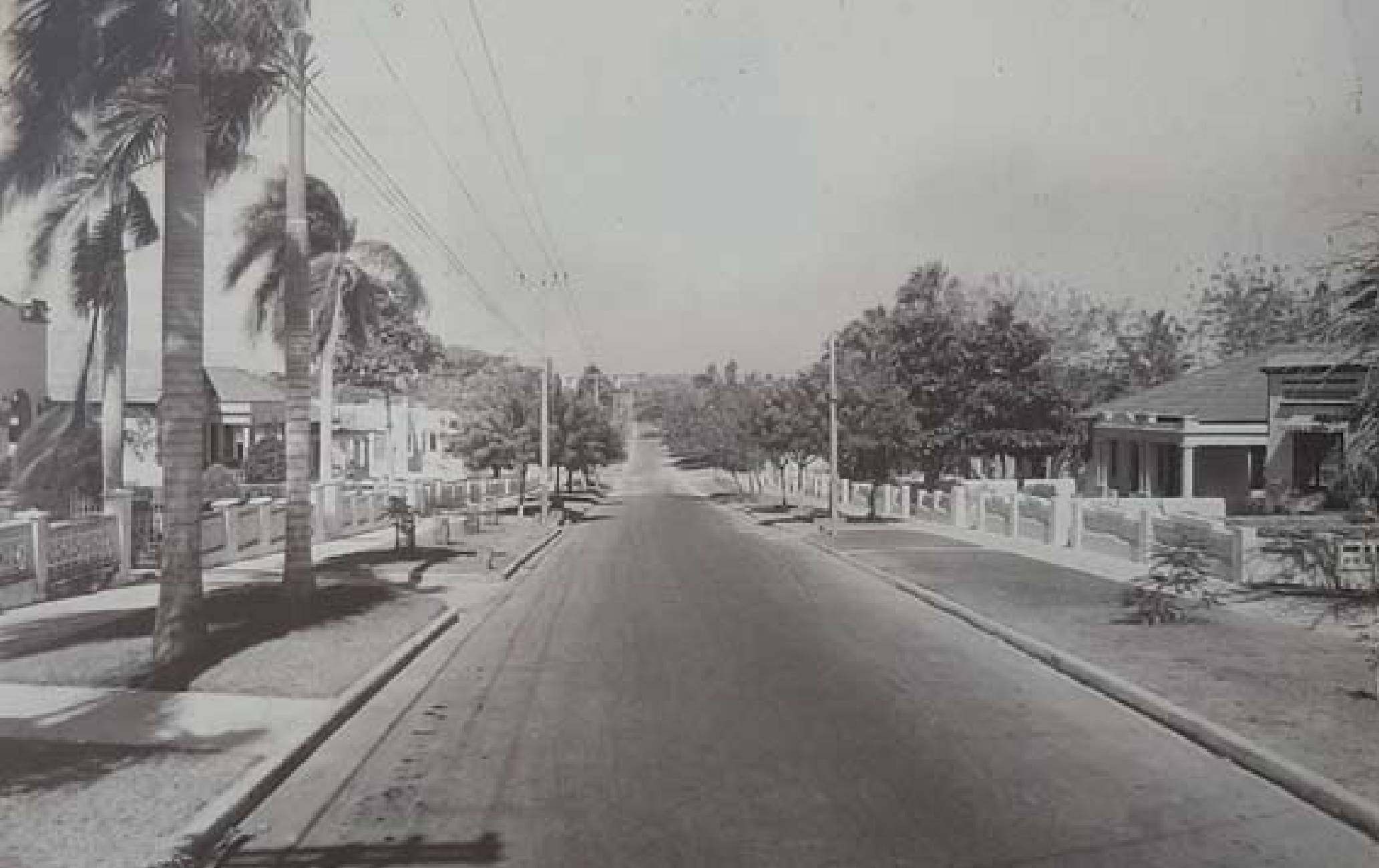

Imagen 6. Barrio EL Prado. Avenida Colombia. Fuente:

Ferro-Bayona, J.; Llanos-Diaz R. (2016).

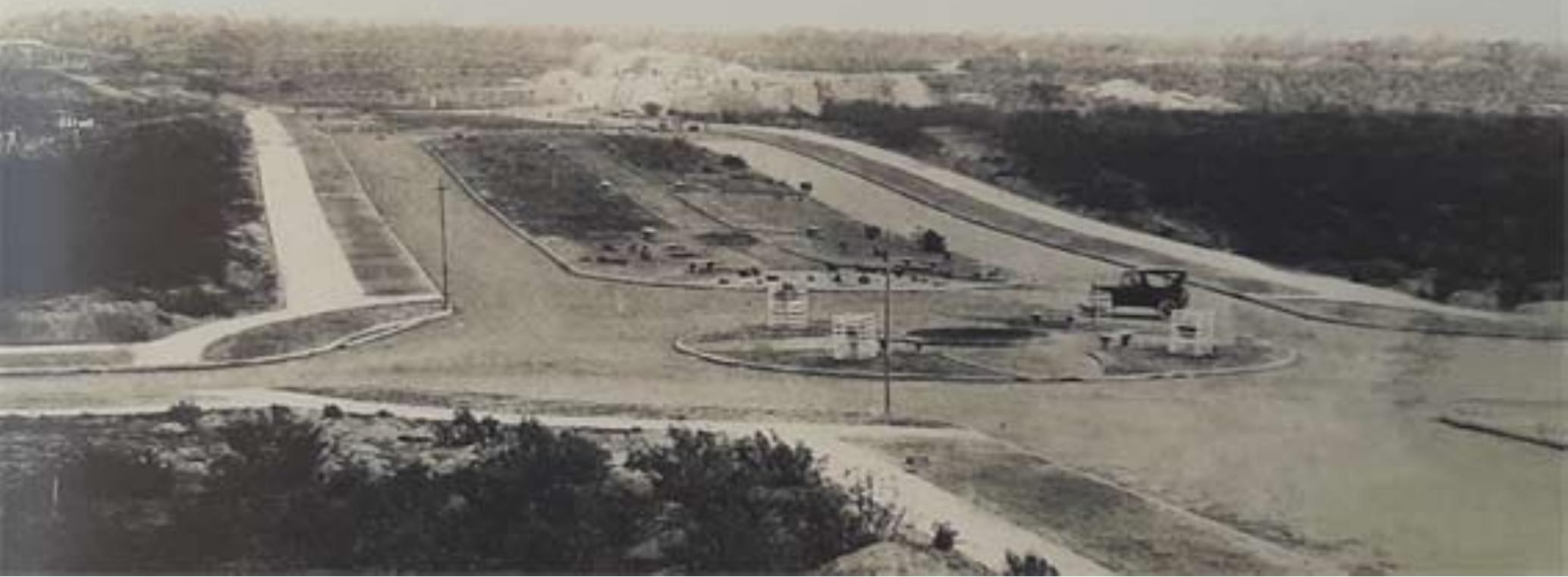

Imagen 7. Barrio EL Prado. Boulevard Sur. Fuente: FerroBayona, J.; Llanos-Diaz R. (2016). 
sino también en el patrimonio cultural como estructurante de cualquier proceso. En ese orden de ideas, es fundamental que:

1. Se recupere la Memoria Urbana del Barrio, poniendo el valor histórico del patrimonio tangible e intangible en el discurso colectivo de todos los ciudadanos. Es un ejercicio de empoderar al ciudadano para liderar los procesos de revitalización del barrio, generando por consecuencia un empoderamiento colectivo.

2. Se desarrolle un proceso de Regeneración Urbana, protagonizado por el reciclaje urbano de casas y edificios en desuso, proponiendo nuevos usos orientados a la cultura y la reivindicación de esa memoria: Museo, Casas culturales, etc.

3. Se promueva la recuperación y consolidación del Paisaje Urbano, planificado en la Genesis del proyecto en el que el verde urbano sea el gran protagonista.

4. Desarrollar un sistema comunicacional que permita a ciudadanos y visitantes, leer, sentir y vivir la memoria del Barrio Prado, con elementos de señalética organizados, manteniendo una identidad propia del barrio y con criterios inclusión social y accesibilidad universal.

5. Se garantice un criterio apropiado (una visión) para transformación e intervención de las edificaciones con declaratoria patrimonial, que les dote de una actividad particular, garantizando que todos ellos cuenten con un uso o función, bien sea privado, público o colectivo. Y que, pese a la idea de restauración y conservación del patrimonio, no restrinja una visión del patrimonio como una cuestión de futuro.

PATRIMONIO, CULTURA Y REGENERACIÓN URBANA, TRES ASPECTOS CLAVE PARA EL FUTURO DEL BARRIO EL PRADO.

La regeneración urbana en términos generales es un ámbito que involucra lo económico, lo social, lo político y lo cultural principalmente (Remesar y Ricart, 2013). Aunque para Moserrat Simó (2013): "La regeneración urbana en el ámbito residencial, se queda mucho más acotada y tiene más relación con la revitalización urbana". La regeneración urbana se puede definir como un proceso de transformación de un entorno urbano a través de acciones e intervenciones físicas y sistemáticas tanto en la gestión del territorio urbano, como en la construcción de planes, programas y proyectos que ordenen dicho proceso. Por lo tanto "el concepto agrupa realidades diversas y dispares, referidas a prácticas de renovación del tejido urbano mediante programas intensivos" (Remesar, 2019).

Ahora bien, a estas alturas es evidente el valor patrimonial que tiene el barrio El Prado y su condición como monumento: "inseparable de la historia de la cual es testigo y del medio en el cual está situado" (López, 2019). Y en este sentido, el proceso de regeneración urbana que se visiona tiene el factor patrimonial 


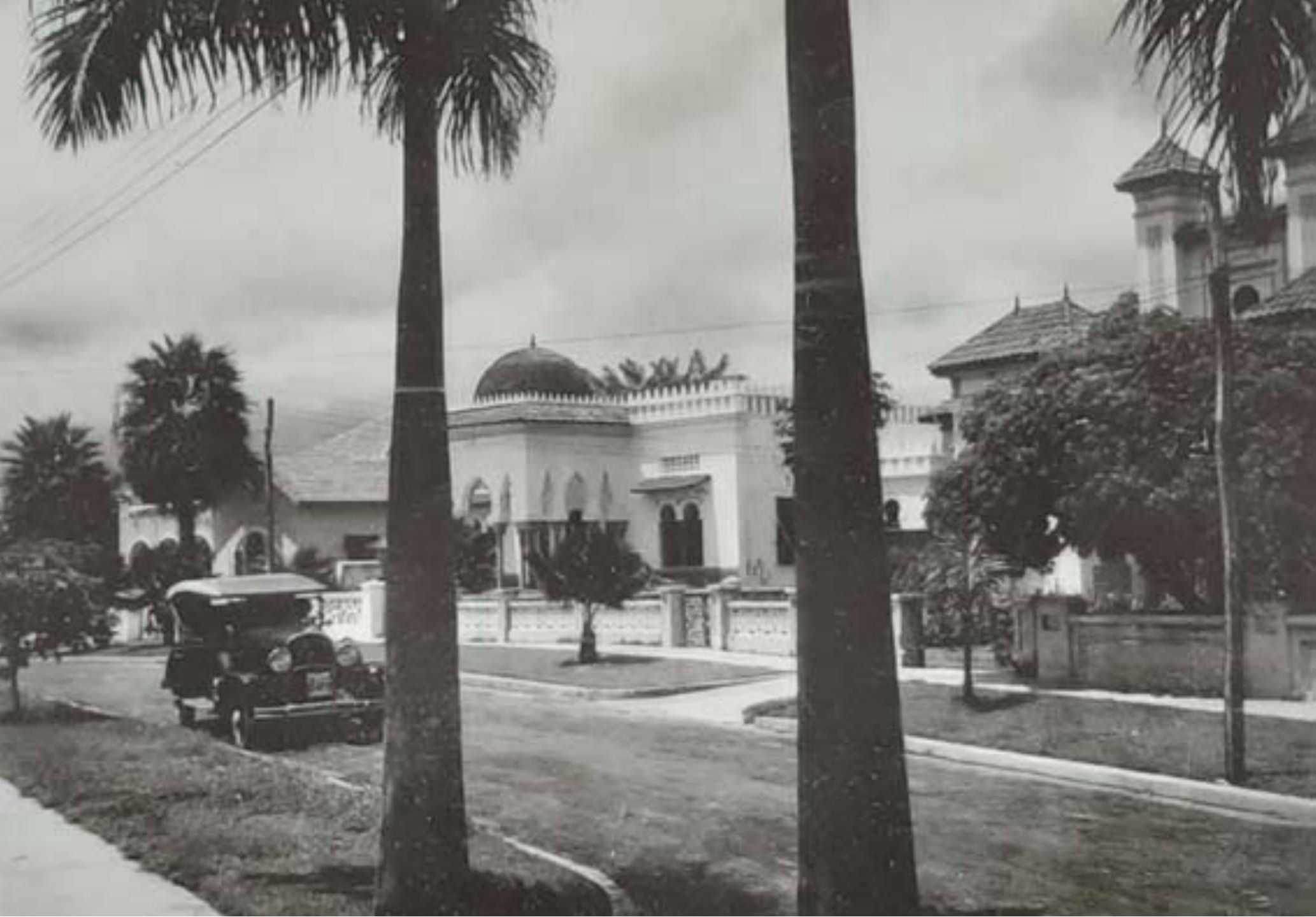

Imagen 8. Vista de la Calle 67. . Fuente: Ferro-Bayona, J.; Llanos-Diaz R. (2016).

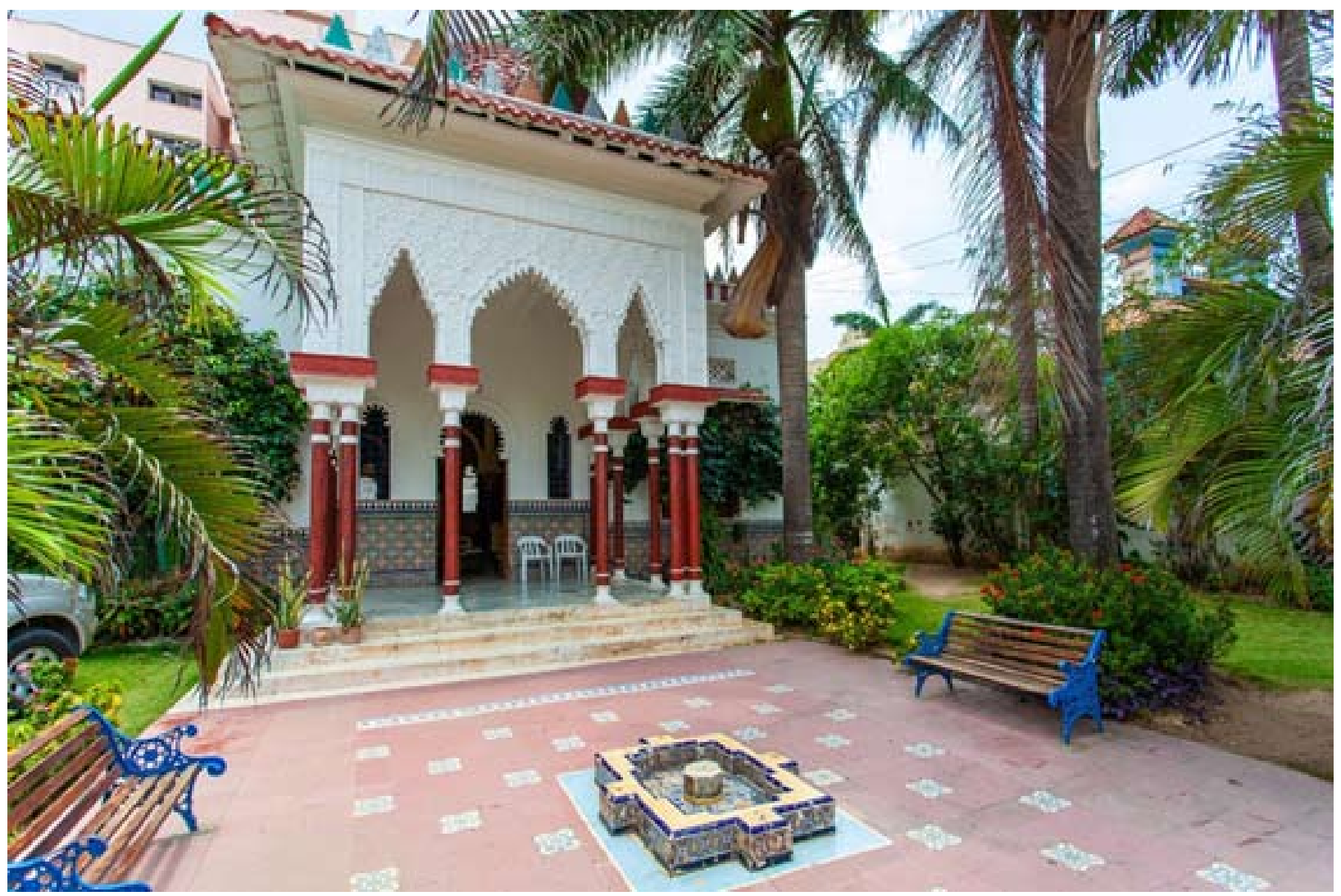

Imagen 9. Casa Barrio El Prado. Estado actual de una casa con estilo árabe, su uso en la actualidad es comercial, lo que garantiza que se pueda mantener en buen estado y a la vez guarde un poco de la memoria. (C) Juan Tapias Martínez 


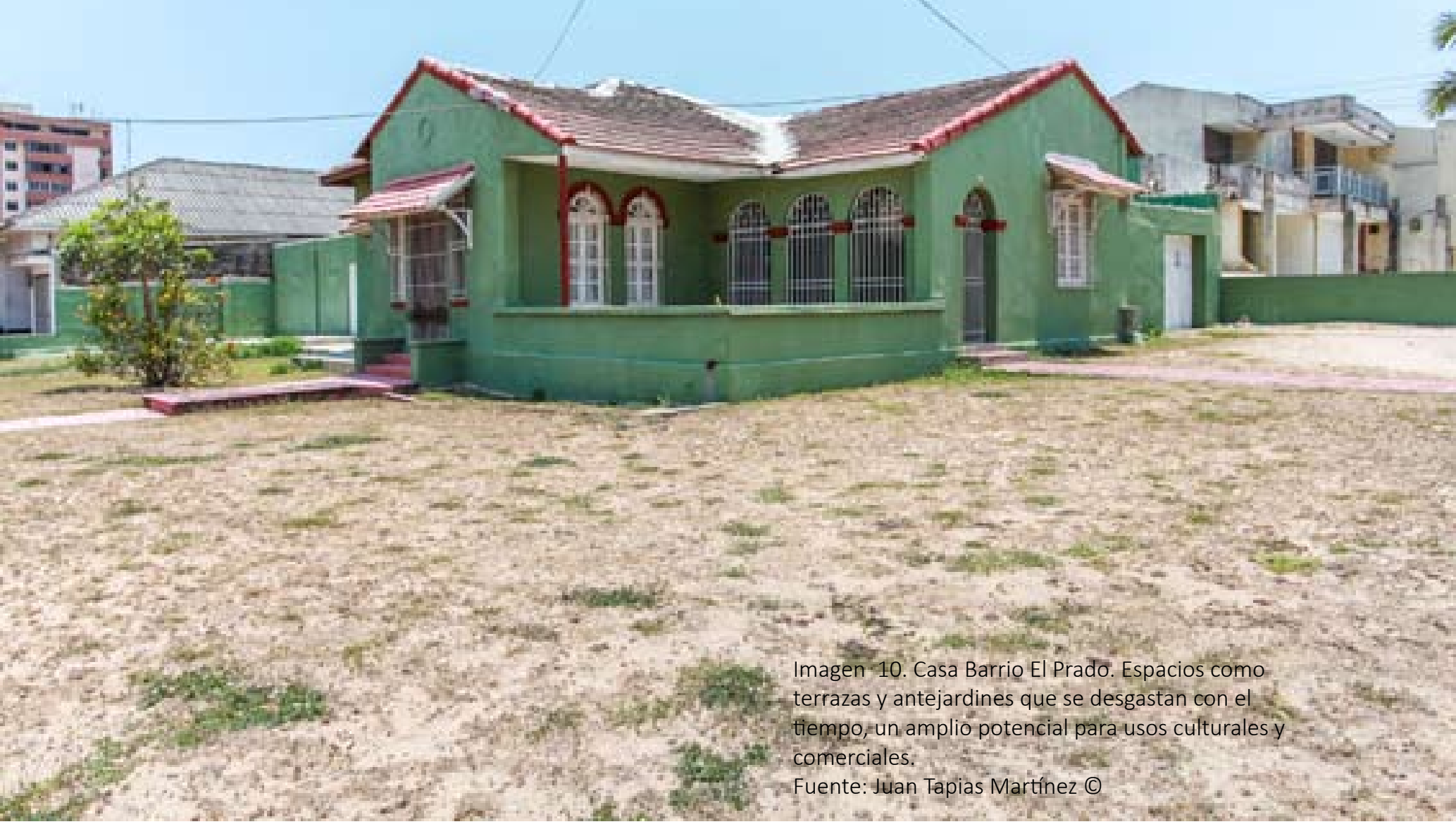

como estructurante de cualquier estrategia de desarrollo para el barrio. En la radiografía en la que se posa la idea de convertir el Barrio El Prado en un museo vivo, el patrimonio aparece como una cuestión de propiedad asumida, heredada o legada. Es decir, de aquello que tiene un valor, un significado desde lo poético, simbólico, lo técnico, lo sistémico, lo morfológico, que puede y debe ser conservado, gestionado y proyectado. Y esto implica asumir el termino no sólo desde una realidad tangible, sino desde todo aquello que es intangible, que estructura y otorga identidad a los espacios y escenarios ${ }^{4}$ donde ocurre la vida de las personas (la ciudad y sus partes: la casa, edificio, espacio público, el barrio, etc.). ${ }^{5}$

El patrimonio en este sentido, resulta ser un activo para las ciudades y tiene tres tiempos para ser abordado, (1) el pasado, el que reivindica la memoria, (2) el presente, que es la gestión y mantenimiento y finalmente (3) el futuro, que es el que tiene que ver con el desarrollo (Wolf, 2016). En estos tres tiempos se entrelazan las capas de lo técnico, poético y simbólico. Así pues, el patrimonio tiene muchas más oportunidades si se desliga de la concepción vulgarizada de una "cosa vieja" a cuidar, y se entiende como aquello que tiene un valor con el que se puede lograr consolidar el desarrollo físico de cualquier hábitat humano.

4.- En este contexto el valor potencial del espacio público emerge "as a place for the collective expression of the city, able to link and articulate urban territory" donde la "cohesion of urban space is not only related to aspects of its morphology, but is also strongly linked with the existing social and economic dynamics." (Pinto, A., \& Remesar, A. 2015) 5.- Recordemos que la identidad urbana "tiene por base no sólo características tipológicas y morfológicas del espacio público, sino también los significados a través de los elementos transmisores de información simbólica, tanto en sus formas tradicionales (...) como a través de las nuevas tendencias, configurando así una creciente diversidad y complejidad de identidad." (Brandão, P. 2011: 33). 
Desde el punto de vista de la cultura, es detonante a la vez que garante de un proceso de (re) valorización y vitalización de un territorio en concreto. La selección de este territorio, así como su papel de receptor y beneficiario de una serie de iniciativas, queda supeditado a los atributos propios (contenido) que suscitan su selección y la posibilidad que tiene el territorio para ser soporte de nuevas iniciativas y sobre todo vitrina de sus atributos; remarquemos que son estos los que determinarán una mayor o menor viabilidad y proyección, así como también los que cargan de sentido y lógica a la forma de accionar. En este sentido, si nos remitimos a la idea convencional pero esencial a partir de la cual una exposición dentro de un espacio expositivo tradicional, como nos recuerda Kate Fowler (2007), debe establecer una narración que le permita al espectador leer, vivir, experimentar y significar la obra; la experiencia vivencial en el caso que la narrativa esté dada y que ésta sea la obra de "arte" y el escenario, como es el caso del patrimonio (tangible e intangible) arquitectónico ${ }^{6}$ y/o urbano adjudicable a una pieza urbana en particular (Rossi, 1999), la ansiada vivencia se verá superada y exacerbada (Smith, 2012) en cuanto los atributos particulares, el valor simbólico y el significado han sido adquirido mayormente de forma consensuada mediante un proceso temporal que trasciende la inmediatez, posicionándose como un valor activo y transformador de la sociedad.

Bajo este parecer, que entiende a la ciudad7 o parte de esta como una obra "arte": que es narración y escenario a la vez, y que son base significativa en la valorización conceptual de la propuesta de "museo vivo" son reveladores los estudios de Ossandón, Jara y Poblete (2017), los cuales ahondan en las implicancias urbanas que podemos asociar a la experiencia vivencial de un lugar ${ }^{8}$ (Lefebvre, 2013) como puede ser una pieza urbana (barrio) de la ciudad. No solo se reducen a la puesta en valor de los espacios e instancias que la condicionan y definen. "Ia estética de la ciudad no es cuestión ni de belleza ni de fealdad, sino de significados" (Auge, 2000) y estarían dadas por "una resignificación del espacio público y de la vida comunitaria" (Ossandón, 2017), es decir, que está supeditada a la generación de significado como en igual medida a el reforzamiento de la identidad local.

En este sentido, cabe mencionar cierta aprensión que muestran los trabajos de autores como Antonio Remesar (2012), Pedro Brandão (2011), David Harvey (2007) entre otros, al momento que advierten del peligro de que estas iniciativas, al igual que lo sucedido con muchos centros históricos, produzcan resultados muy diferentes a los antes expresados, en cuando a cierta tendencia en la que el uso cotidiano da lugar al consumo, ya sea por la mercantilización ${ }^{9}$ de sus bondades, 6.- "puesto que da forma concreta a la sociedad y puesto que está íntimamente relacionada con ésta y con la naturaleza, la arquitectura es diferente y tiene una originalidad con respecto a todo otro arte o ciencia" (Rossi, A. 1999) 7.- "Volvemos aquí a encontrar la vieja intuición de Víctor Hugo: la ciudad es una escritura; aquel que se desplaza por la ciudad, es decir el usuario de la ciudad (lo que todos somos), es un tipo de lector que, según sus obligaciones y sus desplazamientos, deduce fragmentos del enunciado para actualizarlos en secreto. Cuando circulamos por la ciudad nos encontramos en la situación del lector de los 100.000 millones de poemas de Queneau, donde puede encontrarse un poema diferente cambiando un solo verso; ignorándolo, somos un poco ese lector de vanguardia cuando estamos en la ciudad" (Barthes, R. 1971)

8.- Para Henry Lefebvre (2013) es un espacio que no es inerte y neutral ya que su producción no solo esta determina por aspectos geográficos, climáticos y antropológicos, sino que está definido por una producción continua de relaciones espaciales: es un espacio social.

9.- En ocasiones los poderes locales para atraer la inversión utilizan estas iniciativas, así como, la ampliación de infraes- 
"lo que implica el predominio de comportamientos vinculados a la experiencia del visitante entre lugares, más que a la del habitante de un lugar" (Remesar y Esparza, 2012) y que a su vez pueden derivar en procesos de gentrificación, privatización y tematización de los valores particulares como también por un exagerado énfasis sobre la preservación y conservación que puede llevar a restringir la evolución de sus particularidades, reduciendo las posibilidades de desarrollo, inversión y emprendimiento local, así como afectar su trascendencia y proyección a futuro.

Ahondado en la línea de refuerzo de la identidad local es significativo el aporte que este tipo de iniciativas, como la denominada "museo a cielo abierto"10", han tenido en una primera instancia en la construcción de la imagen de la ciudad (Lynch, 1960) y en una instancia posterior en la creación de una marca de ciudad (Brandão, 2011). La posibilidad de conjugar en el imaginario colectivo parte del sentir ciudadano, según lo planteado por estos autores, estaría dada por el arraigo y pertenencia que suscita la pieza en la ciudad como por la memoria histórica (compartida) que contiene y representa para un grupo importante de sus habitantes y por tanto en la valoración discursiva del espacio urbano como escenario y soporte de una forma de habitar y vivir.

Bajo este sentir, y abocados al ideal en el que la ciudad al ser narración y el escenario de esta narración la podemos considerar una "obra de arte". Entendemos que el valor asociado al concepto de "museo vivo" se sustenta tanto, en los elementos que habitualmente desde diciplinas variadas (la arquitectura, la historia, el arte, etc.) se asumen como relevantes y significativas para el soporte y contextualización de la narrativa como, en una forma de quehacer ${ }^{11}$ diario (un vivir) digna de reivindicar al nutrir la experiencia narrativa de contenido, significado y realidad.

Desde la perspectiva de reivindicación de una forma de "hacer ciudad" el cuestionamiento sobre la problemática no se centra en el reconocimiento por antonomasia de un modelo histórico importante como el denominado "Prado", sino por la convicción e impronta de una historia, de varias historias que deben ser narradas y valorizadas desde las diversas posibilidades que nutren una forma de sentir la ciudad y lo que se vive en ella.

Ahora bien, desde un punto de vista teórico, si bien la Real Academia Española define el término "regenerar" como "dar nuevo ser a algo que degeneró, restablecerlo o mejorarlo", al contextualizarlo en el marco del urbanismo, lleva implícito un restablecimiento o mejoramiento de un determinado sector urbano.

López (2010), equiparándolo a la rehabilitación urbana, lo define como "el proceso de transformación y recuperación del espacio urbano, sea del tipo de reabsorción del hábitat insalubre, vía demolición y reconstrucción (slum clearance) o vía saneamiento y mejora (slum improvement); sea por medio de actuaciones urbanísticas de preservación y recualificación del patrimonio edificado con el objeto de mejorar sus condiciones de uso y habitabilidad, conservando su carácter arquitectónico inicial y sin tructuras y equipamientos urbanos en lugares especifico de la ciudad. Lo que, según David Harvey (2007) ha impedido el diseño de un planteamiento urbano integral.

10.- El concepto de museos a cielo abierto alude a la idea que la ciudad en parte es un museo. Donde ciertas edificaciones o elementos significativos son representantes de una memoria urbana compartida.

11.- Habitualmente este quehacer en el ámbito de la academia se denomina o se asocia al concepto de patrimonio intangible. 


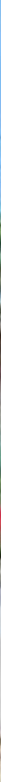

Imagen 13. Casa Barrio El Prado. Mucha de la infraestructura patrimonial está en venta, grandes casas que en la época dorada de la ciudad albergaban familias enteras, ihoy esperan con paciencia el mejor postor! Fuente: Juan Tapias Martínez (C)

alterar el aprovechamiento de la trama existente, mediante restauración de edificios envejecidos (recycling building) por el paso del tiempo o el descuido de sus propietarios, en distintos sectores de la ciudad, en especial la ruina o estado que condiciona la cualificación jurídica de un edificio, a veces frecuente en avanzado estado ruinoso o en indicios en casas de cascos antiguos y de ciertos barrios periféricos"

Y Según Cowan (2005), el término regeneración se hizo común en los 80 (y más ampliamente después de 1995) como un reemplazo para la renovación urbana; un término que se había asociado con el desarrollo comprehensivo y en masa. Fue utilizado inicialmente por el sector privado y se aplicó más tarde a todo tipo de cambio urbano positivo.

La Regeneración es vista además (Couch, Cris et al, 2003) como una respuesta de la política pública a los problemas que han experimentado muchos países de Europa, que tienen que ver con la reestructuración de la base económica de las ciudades, ya que han dejado de ser centros de producción industrial y se han convertido en lugares de focos de servicios y centros de consumo, además de la descentralización o sub-urbanización que ha expulsado muchas funciones fuera de las zonas centrales y del centro de la ciudad hacia la periferia de las aglomeraciones urbanas. Son políticas que intentan recuperar terrenos y edificios vacantes a usos beneficiosos, crear nuevas formas de trabajo donde se habían perdido, mejorar el medio ambiente urbano y hacer frente a una serie de problemas urbanos. Así, el término parece tener sus orígenes en la planeación metropolitana británica a mediados de la década de 1970. Sin embargo, los urbanistas holandeses 
fueron también innovadores en sus planteamientos de renovación de zonas urbanas, especialmente las residenciales desde épocas tempranas. Hacia los 80 algunas ciudades francesas y alemanas adoptaron medidas más o menos similares a las de los británicos.

Como lo manifiesta Cabrera (2013), la figura que se describe

"es una herramienta urbanística y de política pública que se aplica en aquellos sectores de la ciudad que por diferentes motivos sufren de deterioro físico de sus infraestructuras (en diferentes grados), problemas sociales, pérdida de población que genera disminución de las densidades y poco aprovechamiento del suelo urbano. La intervención está encaminada a la corrección de esas deficiencias a través de una intervención urbanística en diferentes niveles multidisciplinarios (social, ambiental, económico y cultural) y tiene como objetivo la recuperación, restauración y saneamiento de las áreas conservables, tanto por su posibilidad de reutilización como por su valor histórico (...). Los fines de esta intervención, los cuales pueden ser valorados en menor o mayor grado, dependiendo de la naturaleza del proyecto, consisten en generar un mejoramiento de las condiciones de vida de los residentes, así como de las condiciones ambientales, de desarrollo económico, social y cultural del sector y por ende de la ciudad".

Ahora bien, teniendo claro que el concepto de regeneración es un concepto integral, que abarca el restablecimiento o mejoramiento de diferentes aspectos del sector urbano, como lo son, el espacial o territorial, el de la conservación patrimonial, el social, el económico, y el cultural, es necesario propender por una herramienta que articule cada uno de estos elementos y logre conservar la esencia del barrio, su patrimonio arquitectónico, su tejido social, la preservación de las diferentes especies arbóreas y de fauna pero que al mismo tiempo permita la introducción de usos y actividades que den una segunda vida, un renacer continuo que haga que la coexistencia con esta riqueza ya institucionalizada y legitimada del barrio El Prado, se nutra de las muestras artísticas y culturales a partir de las vivencias que en el presente se desarrollan en el Barrio El Prado y que serán el exponente principal del museo vivo como un patrimonio futurible.

Al posicionarnos en una concepción de regeneración urbana, es importante tener en cuenta las experiencias exitosas en otros países de Latinoamérica, en las cuales la cultura haya sido el factor esencial en la transformación urbana, ya que a través de ella se busca, además de la revalorización del barrio, conservar el tejido social existente, para así generar el empoderamiento de sus residentes, quienes en asociación con agentes del sector creativo podrán configurar una identidad de barrio que integre tanto el patrimonio material como el inmaterial.

La instrumentalización de la cultura como estrategia de transformación urbana en Latinoamérica encuentra sus primeras manifestaciones en Buenos Aires, a finales de los años 90 y primera década del 2000, como lo manifiesta Marcus y Zarlenga (2014), en donde través de diferentes políticas públicas direccionadas por la municipalidad, mediante la Secretaría de Cultura, se buscó 
que la ciudad creara su marca y fuera identificada como "la capital cultural de América Latina", para posteriormente, mediante estrategias de clusterización a través de la constitución de barrios culturales, conformar cuatro clases de Distritos (tecnológico, audiovisual, artes y diseño) que surgen como nuevas centralidades, generando empleo, fomentando el turismo cultural y revitalizando la economía del barrio.

Estos distritos están conformados por algunos barrios de Buenos Aires, que comparten "elementos comunes" patrimonio simbólico y cultural acumulado durante tiempo que hace de un espacio un "lugar encantado" para ser usado como escenario de nuevas creaciones, la concentración de creadores, intermediarios e instituciones que forman un denso tejido social, polo emergente de creatividad y la gestación de un estilo de barrios, entre otros (Posso, 2013).

Es así como el primer ejemplo que se presenta es el del barrio Chacarita en Buenos Aires. Barrio que surgió como una "chacra" (finca rural para el cultivo y crianza de animales) Jesuita, en la cual hacia los años 1600, los estudiantes del colegio San Ignacio de Loyola (hoy Nacional de Buenos Aires) pasaban las vacaciones de verano, por lo cual por esa época era conocido como "Chacarita de los Colegiales". Posteriormente, y como consecuencia de la epidemia de fiebre amarilla que azotó a Buenos Aires, ante la insuficiencia de los dos cementerios de la ciudad (Recoleta y Parque de los Patricios), pasó a ser el barrio con el camposanto más grande de Buenos Aires por las más de 5 hectáreas que abarcaba, y desde ese momento fue conocido como barrio funebrero, pues además del Cementerio, se creó el tranvía fúnebre utilizado para llegar a él y, naturalmente, la "estación fúnebre" donde se recibían los ataúdes.

Luego de varios años de funcionamiento, cremaciones, olores y falta de salubridad que afectaba a los vecinos del barrio, el cementerio fue clausurado en 1875 y trasladado hacia el oeste de la ciudad. No obstante, seguía siendo reconocido por esa "histórica etiqueta" y fue hacía el año 2.000 que esto empezó a cambiar, gracias a una corriente artística, cultural y creativa que demostró que "Chacarita estaba más vivo que nunca" (Guillot, 2020).

Desde entonces y hasta la fecha, el barrio Chacarita se ha ido consolidando con la multiplicidad de servicios y actividades que van desde museos, teatros, bares, espacios culturales, salas de teatro independiente, manteniendo la esencia barrial, pero con la creatividad de las nuevas economías locales que van desde la moda, el arte, el gourmet, y actividades al aire libre como talleres de moda, librerías, ferias orgánicas, etc.

El segundo ejemplo, es el barrio Getsemaní en Cartagena, que pasó de conocerse como "El arrabal", por su ubicación periférica en relación con los barrios más cercanos al casco antiguo de Cartagena, a ser uno de los barrios con más vida en la escena de Cartagena gracias a las múltiples muestras artísticas y culturales que encuentran allí sus visitantes. Este barrio de Cartagena se encuentra en la parte externa de trazado del núcleo amurallado y en sus orígenes fue territorio de indígenas, más adelante de inmigrantes que laboraban en el puerto marítimo, tratantes de esclavos, marineros y artesanos (hacia el siglo XVII). 

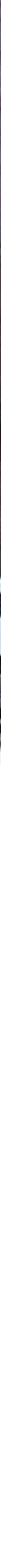

Imagen 14. Barrio Chacarita, March 2015. Fuente: http://allyouseeiscrimeinthecity. com/villa-crespo-chacarita/

Imagen 15. Barrio Getsemaní, Cartagena de Indias. Calle del Pozo.

Fuente: Turismo

Cartagena De Indias. @ CorpoturismoCTG. https:// twitter.com/CorpoturismoCTG/ status/1144185837816619010/ photo/1 
Posteriormente, hacia el siglo XIX, se consagró como territorio de migrantes sirio-libaneses que instauraron comercios en las plantas bajas y residencias en las plantas superiores, consolidando así su vocación comercial hacia 1920 con la inauguración del mercado público de la ciudad, construido en el sector mientras paralelamente se iba desarrollando una marcada vida social y cultural, gracias al establecimiento de teatros en los que se ofrecían espectáculos de cine mudo y combates boxísticos, así como también presentación de artistas nacionales e internacionales (Posso, 2013) y la construcción del Parque Centenario.

Tras este florecimiento del barrio, posteriormente se vivió su decadencia, como consecuencia de la marginalización que sufrió ante la desaparición de estas actividades y por el cierre del mercado, que fueron desplazados paulatinamente por actividades de tráfico de estupefacientes, prostitución e inseguridad que empezó a azotar el barrio. Esto trajo consigo el desplazamiento de la población residente a otros sectores de la ciudad, lo cual impactó en el valor de los inmuebles del barrio, oportunidad que fue aprovechada por los inversionistas que, ante el agotamiento del mercado inmobiliario en los barrios del núcleo histórico, encontraron en la cercanía del barrio Getsemaní la realización de sus negocios comerciales, de vivienda y turismo, generando así actuaciones de restauración, remodelación y construcción en el sector. Entre las diferentes actividades que se han ido instaurando en el barrio resaltan los hostales, hoteles boutiques, restaurantes, bares.

Paralelamente a esta explosión de actividades se empezó a vivenciar un especial interés por la población que aún reside en el barrio, sus costumbres y riqueza cultural que generó un boom de artistas que empezaron a establecer sus talleres de trabajo y viviendas. El principal atractivo que encuentran estos artistas son las dinámicas sociales, la vida de barrio, y como lo manifiesta el artista R.O. (Posso, 2013) "el barrio puede ser interesante para los extranjeros debido a que Getsemaní es la vida en ebullición, siendo atractivo ese "vivir para fuera" que puede resultarles una terapia".

La explosión de muestras artísticas y culturales han convertido al barrio Getsemaní en un lugar apetecido por los artistas que han encontrado en él, el escenario perfecto para sus realizaciones audiovisuales nacionales e internacionales, así como para el establecimiento de obras de artistas que encuentran en el barrio un valor simbólico y cultural, y además ha incentivado el surgimiento de colectivos culturales y artísticos así como asociaciones cívicas de vecinos que se apoyan para luchar contra la gentrificación que se produce generalmente con una transformación urbanística de estas características y quienes aprovechan este nuevo florecer de su barrio para realizar diferentes tipos de festivales gastronómicos, musicales y artísticos.

Por las anteriores características, el barrio Getsemaní es uno de los ejemplos latinoamericanos de barrios que han sufrido una transformación urbana teniendo a la cultura como principal agente catalizador de esa "nueva vida". Como se señala Rius y Posso (2016): "la clusterización cultural genera beneficios por la concentración y la densidad de intercambios entre agentes culturales (Markusen, 1996), (Markussen y Godwa, 2010), y que su importancia no se deriva solamente de factores infraestructurales (Scott, 2000), sino de las relaciones sociales formales e informales que 
permiten formar una escena creativa (Currid, 2007; Currid \& Williams, 2010)".

Independiente al alcance y magnitud que podemos asociar a una experiencia en particular, cabe mencionar cierta discrepancia o aprensión inicial en relación con el uso selectivo de la cultura como instrumento de éxito. Lo anterior, en cuanto a que la cultura puede ser objeto de intereses sectoriales y partidistas. Ahora bien, esta aprensión puede ser matizada en cuanto dichos intereses, debidamente integrados dentro de un proceso de reconversión o regeneración, puedan tener un impacto positivo en el posicionamiento, validación e interés de la cultura como instrumento significativo para la mejora de las condiciones de vida en la ciudad o en una parte de ésta.

\section{LA IDEA DE MUSEO, UNO VIVO...}

La construcción de la narrativa de regeneración urbana hacia el Barrio Patrimonial El Prado, que conjuga tanto el escenario como la escena del habitar, ha conducido esta investigación a conciliar estas cuestiones en un concepto que saca al museo de la caja y lo traspone en un barrio, siendo lo protagónico, la condición viva del barrio, las situaciones cotidianas que en este lugar son inherentes al patrimonio. Para ello se ha ahondado en el significado de museo y de allí se explica su derivación.

Museo deviene etimológicamente del latín museum y este del griego moyseîon, que significaba lugar consagrado a las musas (Corominas, 1980). En la antigua Grecia estaba referido al lugar donde se cultivaban las artes literarias, la academia de filosofía, la biblioteca y a las grutas adornadas en las villas griegas (Corominas, 1980). Por otra parte, el diccionario de la Real Academia Española (2020) deriva su definición mediante cuatro acepciones:

1. "1. m. Lugar en que se conservan y exponen colecciones de objetos artísticos, científicos, etc.

2. m. Institución, sin fines de lucro, cuya finalidad consiste en la adquisición, conservación, estudio y exposición al público de objetos de interés cultural.

3. m. Lugar donde se exhiben objetos o curiosidades que pueden atraer el interés del público, con fines turísticos.

4. m. Edificio o lugar destinado al estudio de las ciencias, letras humanas y artes liberales."

La primera lo refiere como el lugar de objetos de cualquier índole, en este sentido inertes o inanimadas, para su conservación. La segunda lo precisa como una institución sin beneficios, esto es un organismo establecido regido por normas, reglamentos, etc., que adquiere mediante sistemas de mercado los objetos de colección para generar aportes culturales. La tercera está dirigida hacia los modos de vinculación con el espectador y un alcance que puede traspasar lo cultural y recreativo local para derivar en una condición turística. La cuarta le asigna la característica de recinto, en el cual, se estudian tres ramas del conocimiento: científico, humanístico y artístico. 
Una tercera incursión para el desarrollo del concepto de Museo Vivo se realizó en los archivos del El ICOM, Consejo Internacional de los Museos, órgano "cuya finalidad es investigar, perpetuar, perennizar y transmitir a la sociedad el patrimonio cultural y natural mundial, presente y futuro, tangible e intangible" (ICOM, 2007). Institución perteneciente a la UNESCO que, desde su fundación, ha postulado tres definiciones, siendo la vigente, la propuesta en 2007, la cual define al museo como

"una institución permanente, sin fines de lucro, al servicio de la sociedad y abierta al público, que adquiere, conserva, estudia, expone y difunde el patrimonio material e inmaterial de la humanidad con fines de estudio, educación y recreo por lo general es un edificio en cuyo interior se albergan colecciones de arte, ciencia, etc." (ICOM, 2007).

Esta concepción de museo para el ICOM se encuentra actualmente en modificación y con una propuesta de la junta directiva elaborada en su 139 sesión, la cual amplia el sentido político del museo, cualificándolo como lugar para la democratización, inclusión y diálogo de asuntos pasados y futuro en reconocimiento del desarrollo del presente. En esta propuesta los museos pasan a ser custodios de objetos y guardianes de la memoria, garantizando a todos su acceso igualitario. Se proponen desde aquí como lugares de participación, convergencia y confianza hacia y con las comunidades " a fin de coleccionar, preservar, investigar, interpretar, exponer, y ampliar las comprensiones del mundo, con el propósito de contribuir a la dignidad humana y a la justicia social; a la igualdad mundial y al bienestar planetario" (ICOM, s/f).

Es así como el origen etimológico, la concepción de Museo del ICOM, los procesos de regeneración urbana, el significado de la ciudad desde el arte, el patrimonio como cuestión de futuro y las experiencias en el Barrio el Prado, se han conjugado para concebir la regeneración de una zona patrimonial como un museo vivo. Un museo vivo que trascienda las formas de museos vivos ya conocidas: 1) Los museos vivos de carácter representativo, que buscan recrear escenarios para replicar hechos del pasado, lo que pareciera más un acto escenográfico que mediante la actuación trae al presente algo que ya no existe. 2) Zoológicos y jardines botánicos, los cuales trabajan con especies vivas (flora y/o fauna), por ejemplo, un zoológico, un jardín botánico, etc., cuyo valor está en el objeto animado que es sacado de su contexto y llevado a ese lugar recreándole las condiciones para que "viva". 3) Los eco-museos, museos del barrio y museos comarcales se desarrollan como espacios de desarrollo social, económico y cultural con el fin de promover su patrimonio (Moutinho, 2010; Corral, 2012).

El Barrio El Prado concebido como museo vivo en primera instancia, es un museo que no saca de contexto la colección, la mantiene en su sitio, ya que ésta no es estrictamente un "conjunto ordenado de cosas, por lo común de una misma clase y reunidas por su especial interés o valor" (RAE, 2020), sino que constituye el conjunto de situaciones, cosas que, ya están reunidas en un sitio determinado y en su agrupación nos dan una co-lección, esto es una lección colectiva de que este medio construido hace ya cien años, continua como organismo vivo funcionando y 
constituyéndose como lugar de ejemplo en la ciudad, región, país, Latinoamérica y el mundo. Es así como, lo vivo en este Museo toma partida del sistema espacial cultural dinámico, simbiótico y equilibrado socialmente. Un espacio que surge de forma natural y que se encuentra en constante crecimiento, donde sus habitantes recrean espontáneamente la vida de barrio, la fundamentan y sustentan, pero a su vez la aprovechan en un sistema de equilibrios económicos y culturales donde las dinámicas que atraen el boom comercial los empodera y los valora como pieza fundamental del complejo sistema.

La complejidad que trae un sistema vivo en términos ambientales y urbanos implica una Revisión sistémica de los constructos que validan la idea de barrio desde su concepción hasta nuestros días. El barrio es una creación espontánea que conformó la evolución urbana de nuestro mundo citadino, constituyendo la idea de una comunidad que crecía en igualdad de sueños y aspiraciones de idoneidad urbana para sus habitantes. La idea de barrio nos arropa desde nuestra formación como ciudadanos, de cómo nacimos y nos hicimos en un ambiente social y equilibrado, dados ciertos factores según la ubicación y el estrato que nos vio crecer.

"En muchos casos, según sus dimensiones y envergadura, puede coincidir, rebasar o ser contenido por los límites del "barrio político-administrativo" o del "barrio antropológico". Sin embargo, en cualquiera de los casos, el barrio delimitado en sentido urbanístico preexiste como una suerte de hito histórico material e ideológico, una suerte de momento cero" (Urquizo, 2006)

Un museo que como espacio democratizado (ICOM,s/f), muestre cómo sus dinámicas cotidianas cohabitan en un medio urbano de tal trayectoria y que es la integración entre las formas de vida del ciudadano común en su diario hacer, que lo mantiene como un lugar para realzar sus potencialidades dentro de una cuestión de patrimonio como futuro. No se trata de crear un medio inerte intocable, sino por el contrario de permitir de manera consciente acciones que potencien esas dinámicas. Una cuestión que a nivel mundial lo están desarrollando los museos hoy en día (Moutinho, 2010), buscando la manera de activar el lugar para atraer a las personas. Teniendo entonces este lugar que es patrimonio histórico de la nación, que es un organismo vivo, solo falta sacarlo a la luz y para esto es que se propone constituirlo como "Museo vivo".

Si este sector de la ciudad se considerará como museo, es necesario conocer las partes de un museo para poder extrapolar sus elementos constituyentes: Si en un museo el edificio es el lugar para albergar lo valorado, en el museo vivo es el paisaje urbano que como tal se asume como lugar a valorar y destacar. Si en un museo se albergan obras y objetos que son sacados del contexto y se les confecciona una museografía, en el museo vivo, en su lugar, los edificios se transforman en puntos de interés, la flora, la fauna, las vistas, las situaciones, los lugares propios, todo en su ambiente constituyen su valor. Si en un museo las fichas técnicas son las que comunican el qué, el cuándo, el cómo, el quién de la pieza a exponer, en el museo vivo es el pavimento rodado y la realidad amentada los medios a través del cuales se comunicarán los aspectos relevantes de cada lugar, situación, vista, etc. Si dentro de un museo para cada exposición se requiere un muro 
titular donde se exponen los datos y textos de cada una de ellas, en el museo vivo cada una de las entradas al sector, es decir las bocas de calle serán los lugares propicios para inscribir la información requerida para definirlo y delimitarlo, al mismo tiempo que se podrá curar lo que se encuentre en esa vía. Si en un museo las exposiciones son registradas en libros como catálogos, en el museo vivo las cartas de las derivas urbanas son el catálogo del museo, ya que un museo vivo no es un lugar acabado, lo que hace que un juego de cartas sueltas, que puedan irse ampliando, dejen en manos del paseante su experiencia. En el museo las exposiciones son visitadas por espectadores, en el museo vivo el lugar es visitado por exploradores ávidos de disfrutar conocer la historia viva del sector.

Es entonces como el museo vivo es construido por el presente que ha sacado partido del pasado y lo posiciona en él como cuestión de futuro. Un museo fundado en la vinculación que existe entre el espacio y la idea de lugaridad, de la cual derivan la singularidad urbana, como expresión representativa y significativa de la construcción física y perceptual de la ciudad. Aquí la noción de museo bajo la lógica de ser considerada obra "arte", responde a las propuestas conceptuales desarrolladas por Pontus Hultén y Harld Szeeman (Obrist, 1996) las cuales se alejan de la idea convencional, pero necesarias para considerar la necesidad de establecer una narración para un museo concebido como un espacio elástico, abierto, permeable y cambiante.

Es así como este Museo se funda en la realidad como aspecto elemental de la experiencia y por ende la narrativa reconoce en la diversidad, simultaneidad y casuística ${ }^{12}$ de encuentros y relaciones, el carácter esencial del habitar, es decir, lo fundamental de la incorporación activa de los habitantes (su vida diaria) en la construcción de sentido y significado a revindicar. Reflejo de lo anterior, es la (pre)existencia de una serie de instancias urbanas (lugares y actividades) ${ }^{13}$ en la que se apoya y se proyecta dicha construcción en el tiempo. Esto sugiere, que dichas instancias urbanas (atractivas) como expresión tangible para el espectador o visitante de la forma de habitar (cultura local) cuentan con un "reconocimiento social y cultural por su continuidad temporal en el espacio, el conocimiento transmitido, su relación con procesos históricos, la representatividad que tienen para algunas personas y grupos sociales en la cotidianidad, su relación con aspectos materiales del patrimonio y el sustento que proporcionan a quienes las han desarrollado" (IDPC, 2020), fomentado y proyectando en última instancia una serie de fructíferos intercambios ${ }^{14}$ que,

12.- Desde el punto de vista de la posibilidad de encuentro múltiples y relaciones simultaneas "La casuística que genera el cúmulo de materia urbana y conexiones selectivas entre lugares de acúmulo, configuran una jerarquía espacial más compleja y mayor a la morfología visible o tangible de una ciudad o lugar" (Reyes Schade, E. 2017: 594), lo que, a su vez nos plantea la "paradójica sensación de estar habitando realidades locales y globales simultáneamente" (Greene y Mora 2011: 33).

13.- La red de comercio local es un interesante ejemplo que grafica el carácter esencial del habitar en la construcción de sentido y significado, al dotar al escenario de contenido mediante una serie de sucesivas capas de relaciones e intercambios que sugiere un entretejido complejo y dinámico entre el material fijo, es decir, lo material y sus diversas escalas y dimensiones y el flujo que suscita la interacción humana (Dupuy, G. 1998).

14.- "Definir el cómo se relacionan diferentes entidades en pos de una totalidad abierta, determina la forma en la cual se estructura la misma, así como también, la forma de como interaccionar con un medio determinado a partir tanto de las necesidades in-ternas como externas apunta a concretar entidades de continuidad, interactuantes y polisémicas de limites variables y adaptables según la diversidad en su interpretación metafórica y material" (Schade, E. R. 2018: 10) 


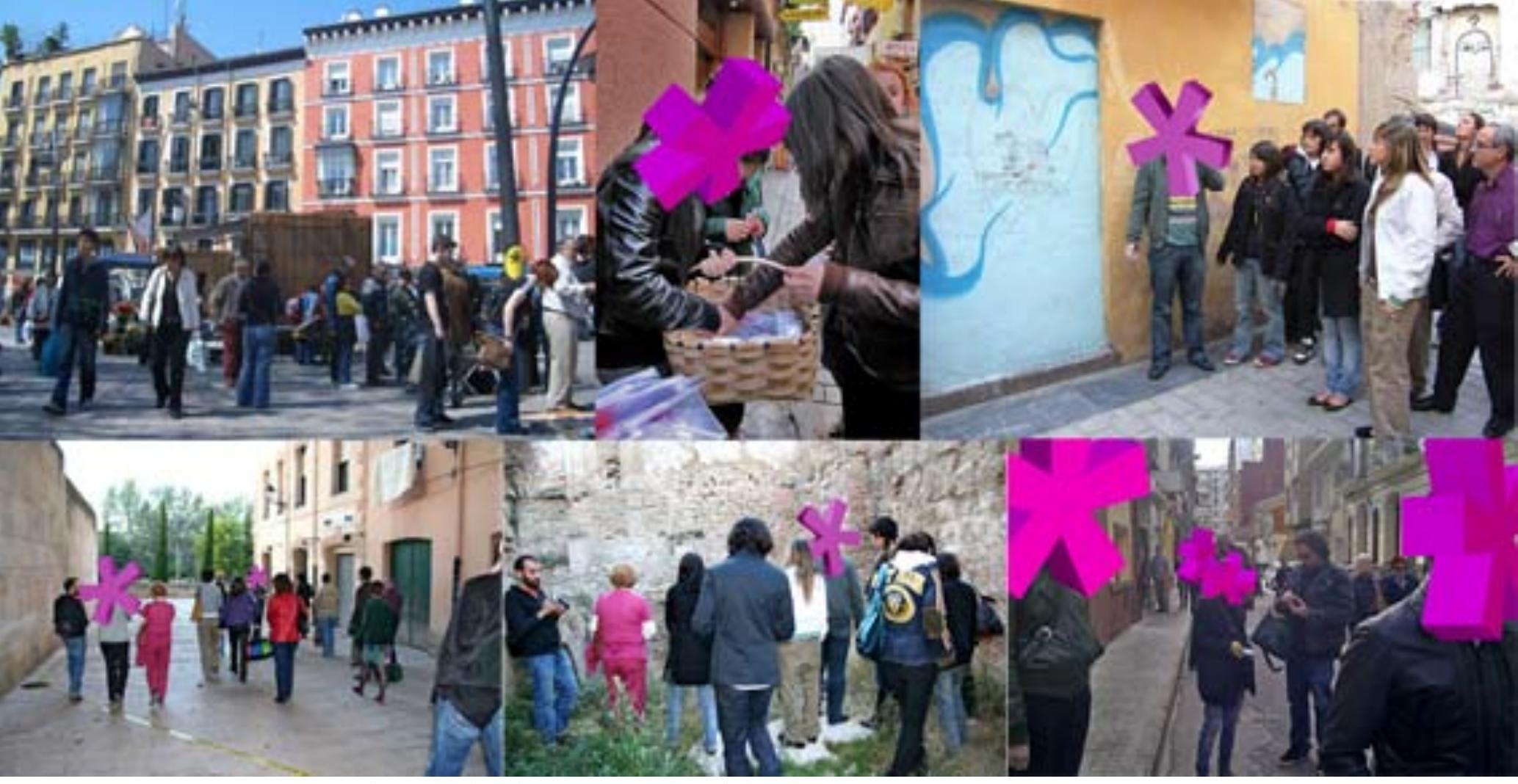

Imagen 16. Recorridos a través del MURAC y su identidad anónima.

Fuente: https://www.flickr.com/photos/murac/5442210133/in/photostream/

para este caso en particular, superan la condición local hacia una proyección global con fuerte carácter local.

Ahora bien, la anterior construcción de la concepción de museo vivo determinó su singularidad en otras formas de museo que se desarrollan en espacios abiertos. Ahora bien, en una convergencia de condiciones, patrimoniales, narrativas, situacionales y espontáneas, se ubicó la búsqueda de otras experiencias que reforzaron y contravinieron la idea de condensar en una construcción colectiva abierta el Museo Vivo El Prado.

Al poseer las condiciones buscadas del Museo Vivo El Prado, se investigó en: museos vivos ${ }^{15}$, museos a cielo abierto, sectores patrimoniales como museos, museos que toman la ciudad y transforman las calles ${ }^{16}$ en museo de arte contemporáneo, así como también el slogan del que hacen uso muchas ciudades por ser medio de arquitecturas o lugares históricos. De esta manera se construye un itinerario a través de los testimonios que evidencian las cuatro formas de concepción de museo y de espacios públicos en los cuales se han involucrado aspectos museales para reactivación y saneamiento del Barrio patrimonial El Prado.

Esta muestra del estado del arte se inicia con un museo sin sede, transcurre mediante dos museos a cielo abierto, continua con una intervención de espacio público en hibridación con lo museal, atraviesa intervenciones urbanas realizadas desde el museo y culmina en lo que se conoce en Colombia como museo vivo.

15.- Más que hablar de ejemplos y referencia, se denominan testimonios a otras formas de intervención, ya que "para ser viva la experiencia [del museo] tiene que poder ser transmitida y, para ello, necesita del testimonio. Todo testimonio lo es de una ausencia. Su sujeto es el que transmite la experiencia de una desubjetivización. (...) En la acción de testimoniar, en cambio, resulta mucho más importante la experiencia y la revisión de la experiencia por parte de quien la recibe." (Mèlich, J., 2012)

16.- "El arte público está dirigido a la calificación urbana, tanto en términos físicos y simbólicos. En este contexto, podemos decir que, a pesar de las diferencias entre los diferentes períodos históricos, la práctica del arte público que debería ser un aspecto integral de los procesos "hacer ciudad"”(Remesar, A. 2011). 


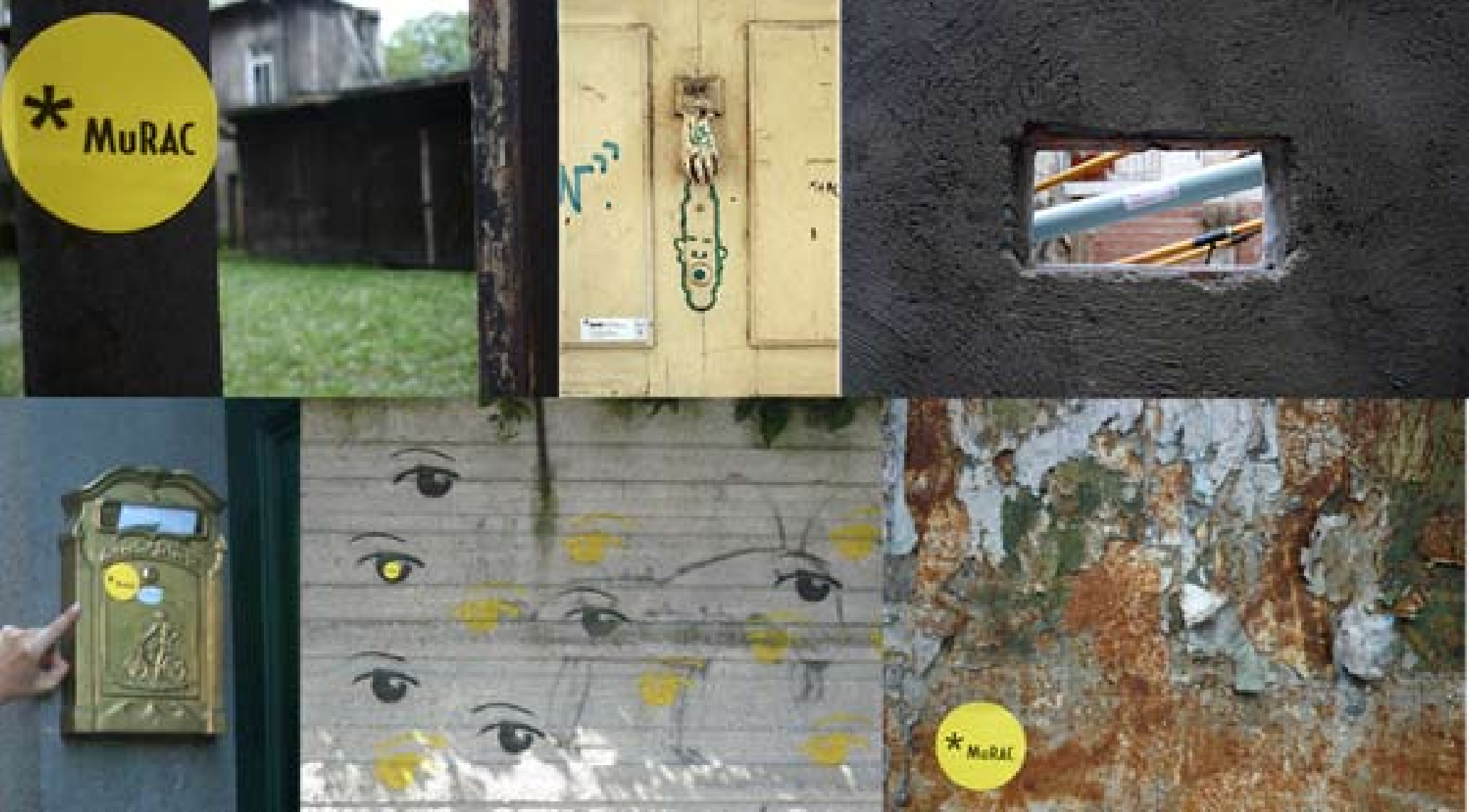

Imagen 17. Muestra de parte de su colección.

Fuente: https://www.flickr.com/photos/murac/5442210133/in/photostream/

El primer testimonio, el Museo Riojano de Arte Contemporáneo, MURAC, una iniciativa conformada por un colectivo de artistas anónimos que, "utiliza la marca-museo como identidad múltiple y trabaja desde el fake, sirviéndose de estrategias propias del arte crítico" (Calvo, 2015).

EI MURAC nace como museo y se constituye como institución, buscando reformular "las relaciones entre crítica e institución" (Expósito, M. En Calvo, 2015) y repercutir de esta manera en el posicionamiento hacia las instituciones culturales por parte del gobierno local. Su finalidad cultural es hacer partícipe a la población de las experiencias de arte contemporáneo y compensar la ausencia de un Museo de Arte Contemporáneo en una ciudad que es capital de una comunidad autónoma. Distanciado de las formas tradicionales de museo, el MURAC

"propone «no distinguir entre continente (la arquitectura) y contenido (las obras)», sino acercarse "al Museo como a un discurso sincrético que se realiza en el espacio» (...) La colección del MURAC está constituida por obras que están en el espacio público. Su colección no aglutina piezas u obras de arte, su labor es la de difundir las prácticas artísticas que surgen de forma espontánea en la ciudad. Su papel de intermediario lo comparte provocando la participación pública en sus acciones". (Calvo, 2015).

Es así como, los curadores del museo mediante la incorporación de fichas técnicas a manera de ready-made, catalogan un universo de intervenciones artísticas o no y lo fijan como parte de la colección. Un museo que no posee planta física como sede, cuya institucionalidad física queda registrada desde una plataforma virtual. Es desde la apropiación, que hace el MURAC, de los elementos urbanos de su ciudad como obra y espacio museográfico y además de la fugacidad 


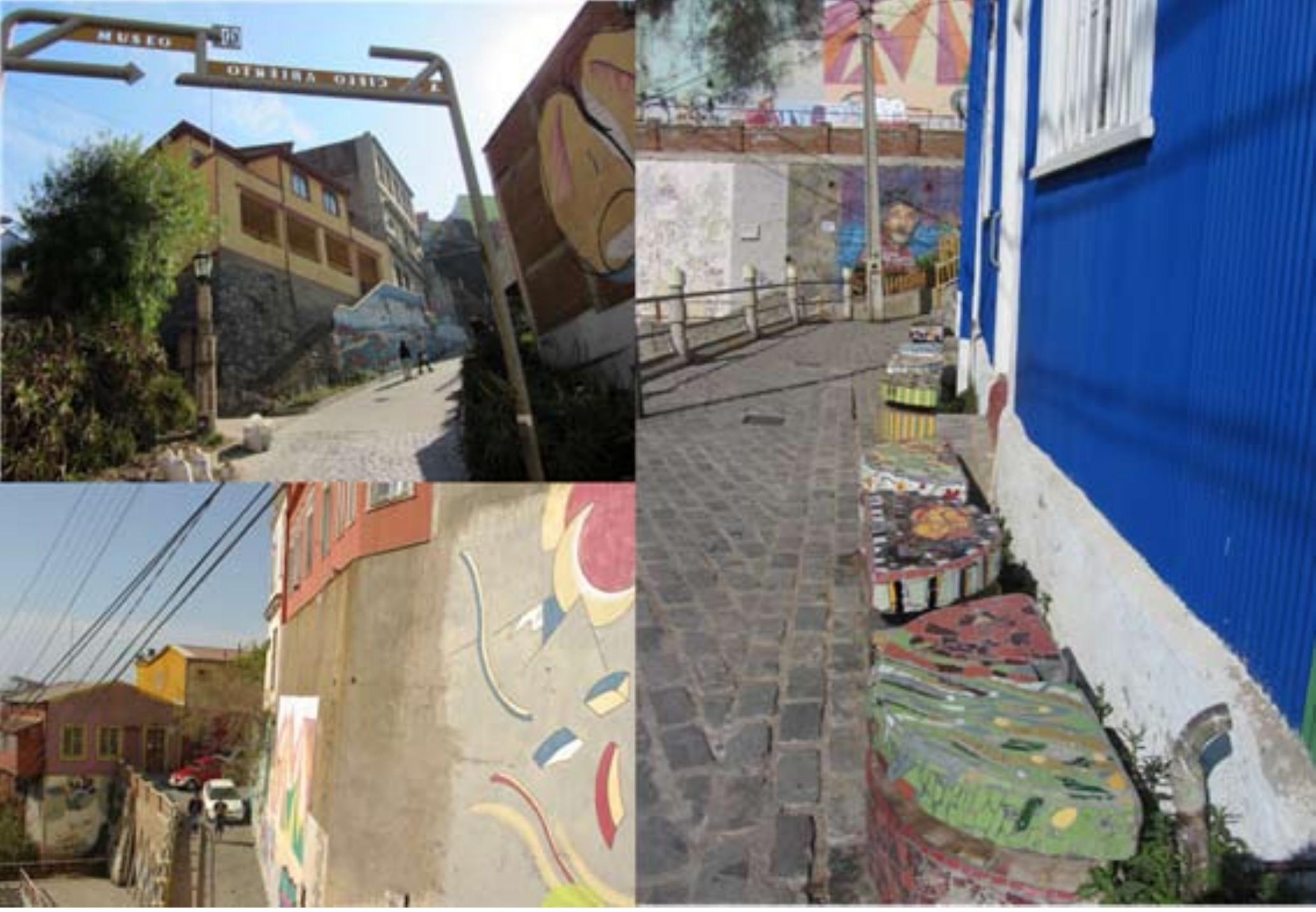

Imagen 19. Museo a Cielo Abierto en Valparaíso. Fuente: https://www.museoacieloabiertoensanmiguel.cl/visita/

comunal a paisaje musealizado, en el cual el museo no se desarrolla dentro de un edificio, sino que, se apropia de las calles y de las medianeras o los muros ciegos de los edificios para exhibir pintura mural que, para enero de 2019 ocupaban un área aproximada de seis mil metros cuadrados. Es un museo que surge desde un modo de reactivación urbana originado en la limpieza de los muros y cuyo artificio artístico, lo conduce hacia una "transformación museística del espacio urbano" (Derosas y García, 2019). Este museo a cielo abierto se diferencia de otros,

"en los «nuevos» elementos patrimoniales que se complementan de manera orgánica en el paisaje. En el caso del Museo a Cielo Abierto en San Miguel, este busca resaltar los elementos comunitarios mediante la ejecución de murales que destaquen valores y características propias de la cultura chilena" (Derosas y García, 2019).

Se instituye como el lugar de mayor expresión de arte callejero en Chile. Sus dinámicas se desarrollan como las de un museo tradicional, esto es: difusión de actividades mediante anuncios públicos y virtuales, apoyo a visitantes, producción de actividades educativas y manejo de políticas de conservación (Derosas y García, 2019). Una comuna que busca el saneamiento del espacio público urbano a través de la intervención mural, así como las acciones llevadas a cabo a través del arte en el espacio público que, desde el decoro, busca embellecer la escena urbana. Traspasando el velo de la belleza visual, se comprende el arte público como parte del Museo Vivo, como un medio para la "generación de ciudades más habitables, (...) sin abandonar los principios multiescalares, 
sostenibles y de innovación urbana como modo de lucha contra la segregación social y que deberían definir las políticas urbanas para el siglo XXI" (Remesar, 2017).

El Museo a cielo abierto Valparaiso, constituye el tercer testimonio que, surge bajo el liderazgo del "pintor, profesor y arquitecto Francisco Méndez y realizado entre 1991 y 1992, cuando convocó a artistas a donar obras que fueron pintadas en muros de un circuito definido en el cerro Bellavista" (Dardel-Coronado, M., 2019). Un museo planificado buscando conciliar la pintura con el paisaje y el recorrido a través del cerro, evidenciando así su carácter curatorial contemporáneo, aunada con una concepción de museo abierto y elástico (Dardel-Coronado, 2019). Una iniciativa que deviene de un actor de las artes por el arte y cuyo soporte de obras son los objetos que configuran el paisaje urbano. Para la conceptualización del Museo Vivo, lo existente en el Barrio no es soporte para, sino que cada uno de los elementos (tangibles e intangibles) que los conforman construyen el museo. Quienes habitan allí, tras la concreción, habitarán en un Museo donde sus dinámicas, concilian una configuración urbana foránea con los modos propios de habitar el Caribe Colombiano.

El cuarto testimonio, el Barrio Museo San Miguel, se desarrolló desde la entidad administrativa del Área Metropolitana de Bucaramanga que, desde un proyecto de mejoramiento de la zona, buscaba transformar la zona de San Miguel en un Barrio-Museo. Esto es un espacio de carácter público que ha sido modificado con la finalidad de que los usuarios experimenten el espacio desde una vinculación con el arte, pudiendo transitar entre obras de gran formato elaboradas sobre los muros del barrio y enmarcados a través de muros que funcionan como dispositivos museísticos, al mismo tiempo que van redimensionando el espacio público. De la misma manera se han realzado los referentes urbanos pertenecientes al pasado del barrio (García-Diaz, 2019). Este espacio público cuyos límites verticales devienen espacio expositivo, saca el arte y el patrimonio a la calle como acto reivindicativo de lo público. A diferencia de la intervención del Barrio San Miguel, lo expositivo, museográfico en el Museo Vivo El Prado, más que enmarcar una parte del patrimonio, busca pasar por desapercibido para permitir que tanto el patrimonio tangible e intangible sean los que se expresen y se funden como bienes protagónicos del Museo.

El Barrio Museo MAC, fue proyecto comunitario propuesto desde el Museo de Arte Contemporáneo de Bogotá con la finalidad de expandir las fronteras del museo y llevarlo a la urbanidad. Este se lleva a cabo mediante un proyecto comunitario de arte urbano, realizado en el Barrio Minuto de Dios de la Ciudad de Bogotá, con la finalidad de: ampliar las relaciones entre el Museo y el Barrio, propiciar vínculos directos entre los artistas y los vecinos, insertar el arte dentro de los espacios urbanos del barrio, realzar el patrimonio cultural existente en el barrio. De esta manera, los artistas se apropiaron de las fachadas de edificaciones, incluso las del propio museo, propiciando desde el arte la vinculación barrio-museo. Es así como este testimonio aporta al Museo Vivo desde la vinculación entre el arte y la comunidad, no solo como un cuerpo de obras que se deja en el espacio atestiguando la relación, sino como acciones activas, programables, itinerantes que reivindiquen el sentido de apropiación de las situaciones y valores patrimoniales del Barrio el Prado.

El último testimonio es el Zoológico de Barranquilla, considerado museo vivo por la propia 


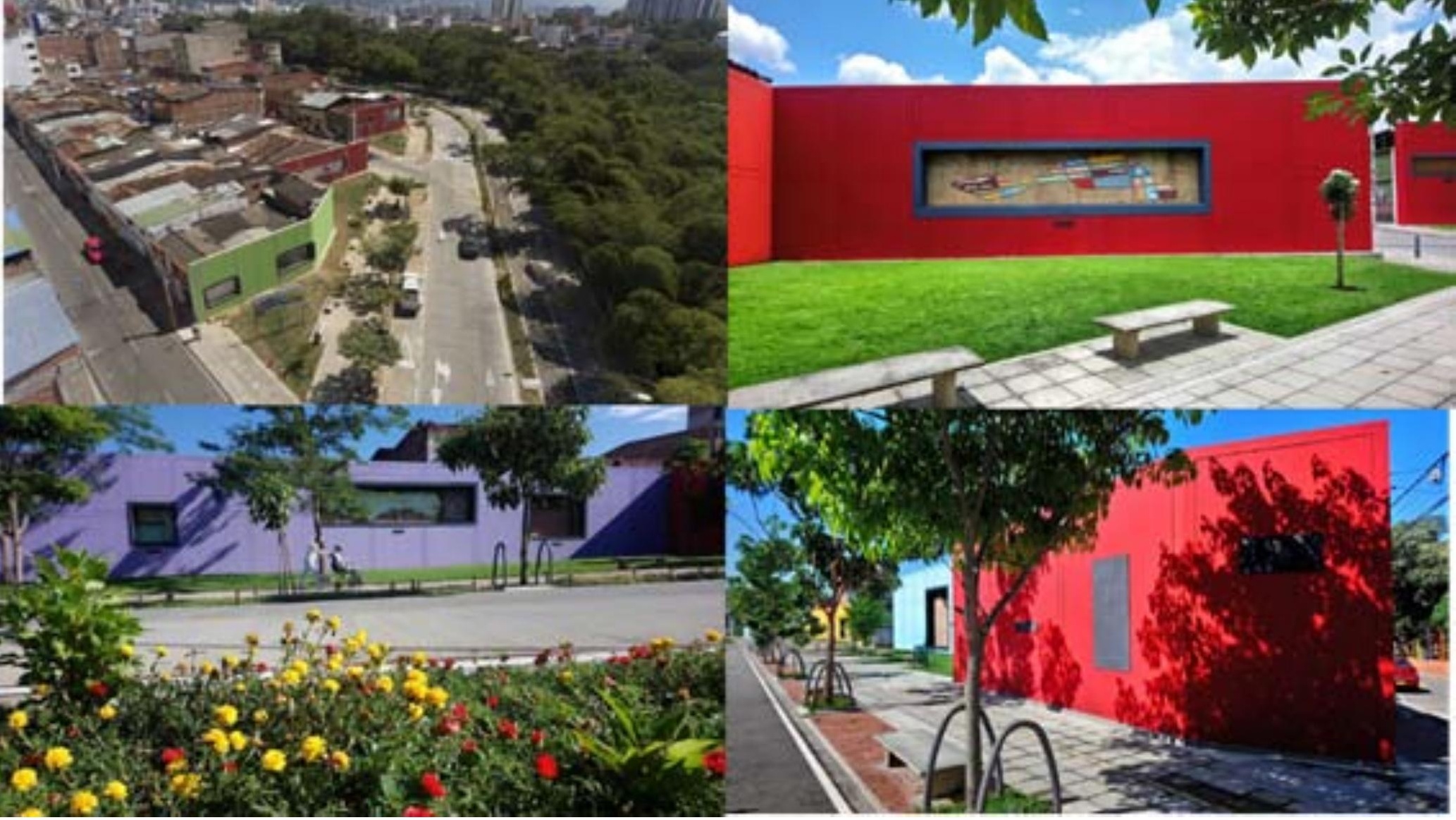

Imagen 20. Barrio Museo San Miguel. Fuente: https://www.amb.gov.co/barrio-museo-san-miguel-bucaramanga-santander/

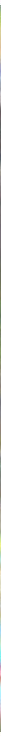

Imagen 21. Intervención del Museo de Arte Contemporáneo de Bogotá en el Barrio Minuto de Dios.

Fuente: https://issuu.com/macbogota/docs/barrio_museo_mac 
institución, que a través de este concepto ha integrado los distintos departamentos del zoológico, en su búsqueda por brindar una experiencia recreativa y educativa a los visitantes sobre las especies que allí se reúnen. El concepto de vivo viene dado por dos razones, la primera, lo expuesto es de naturaleza viva, y la segunda, la interactividad desde la cual se despliega el desarrollo de las visitas y actividades con el público dentro de la institución. Una naturaleza animada que utiliza a la vida animal como espectáculo, apartándolo de su ambiente natural, concepción propia de este tipo de instituciones. Es en oposición, a este concepto de museo vivo utilizado como espectáculo, que se concibe el Museo Vivo El Prado.

En referencia y diferencia a los seis testimonios explicados anteriormente y desde la crítica al actual concepto de Museo del Consejo Internacional de Museos, el Museo Vivo El Prado aprovecha las condiciones del lugar como valor patrimonial en cohabitación con las dinámicas contemporáneas para instituirse como tal.

Es en esta cohabitación de dinámicas que radica la importancia del conjunto patrimonial de El Prado, ya que nutren y diversifican la riqueza de este espacio representativo de Barranquilla, que se consolida como un lugar de intercambios, en el que ocurre una verdadera simbiosis entre lo físico y lo intangible.

\section{MUSEO VIVO EL PRADO UN NUEVO DISTRITO CREATIVO Y DE INNOVACIÓN CULTURAL PARA} BARRANQUILLA.

El Museo Vivo El Prado, propuesto como un distrito de innovación cultural y creativo, resalta el espacio urbano del barrio El Prado desde la cohabitación de sus dinámicas, esto es, la pluralidad de sus vivencias vecinales, expresiones patrimoniales, y desarrollo cultural y comercial, las cuales se determinan como los ingredientes principales para la gestión de una plataforma de actuación urbano - cultural, que los potencialice alrededor de los valores patrimoniales que actualmente ya ofrece el barrio, poniéndolos en escena desde la creación y la innovación cultural.

De esta manera se tiene en cuenta el valor de la cultura en la transformación del barrio, haciendo que los efectos tradicionales y patrimoniales, obtengan una importancia en el desarrollo y determinación del espacio público a partir de la creación y la innovación cultural, y cómo este último factor llega a constituirse como un componente articulador de las dimensiones físicas, sociales, económicas, culturales y políticas del barrio.

La apuesta por la cultura y el distrito cultural no solo generará impacto y retorno económico, sino que puede cambiar los imaginarios colectivos de la ciudad (su imagen) y fundamentar las identidades colectivas (Moralo y Tresserras, 2017). Además, "un área bien diferenciada, etiquetada y de usos múltiples en una ciudad, en la que una alta concentración de servicios culturales sirve de reclamo para el desarrollo de otras actividades" (Frost, 1998). 
De acuerdo con los factores propios de un distrito cultural y creativo, los cuales son: la masa crítica de actores (ciudadanos), la capacidad organizativa del cluster, la proximidad territorial y el marketing territorial (Lazzeretti, 2008), el Museo Vivo El Prado postula la existencia de una masa crítica de actores locales que articula los habitantes del barrio en pro de una autonomía y el desarrollo de una agenda propia, en este caso, lo corporativo, lo comercial, lo patrimonial y lo turístico, alrededor de los aspectos culturales del barrio. De igual manera, una proximidad territorial, la cual establece las relaciones entre la dimensión socio económica y la dimensión institucional. Según esta noción del territorio, los agentes y las instituciones se constituyen en promotores directos del proceso productivo y no en una externalidad (Boscherini y Poma, 2000). Sumado a lo anterior, el Barrio El Prado cuenta con un proceso de transformación orgánico, gracias a la caracterización de su planificación urbana inicial, desarrollo y actualidad, agregado al carácter patrimonial que permite reconocerlo como un entorno urbano con "marca propia", promoviendo una dinámica comercial del barrio, consolidando características proporcionales a las del marketing territorial en cuanto a su reconocimiento y promoción en la ciudad.

Teniendo en cuenta lo anterior, el Museo Vivo El Prado se consolida como un componente de transformación, desarrollo y gestión cultural para una Barranquilla cada vez más identitaria y creativa, que también busca el desarrollo de la economía naranja mediante las industrias creativas y culturales (economía creativa), establecidas en la normatividad colombiana

Detallando los aspectos de la economía creativa como esfera conceptual que contiene la creación y desarrollo del Museo Vivo El Prado, está constituida por la productividad generada de las grandes, medianas y pequeñas industrias culturales y creativas, así como por áreas de la productividad no industriales, como las bellas artes y las artesanías, entre muchas otras. La economía creativa abarca las artes y el diseño, la investigación y la docencia, los festivales y acontecimientos urbanos, la arquitectura patrimonial, las producciones de cine y televisión, el desarrollo de software, los juegos interactivos, entre otros bienes y servicios que se desarrollan esencialmente a partir de la creatividad humana (Prieto, 2012).

Un primer componente importante a tener en cuenta para la proyección del Museo Vivo El Prado y su economía creativa es un conglomerado social que ha sido denominado como "la clase creativa" (Florida, 2010), la cual es un denso grupo compuesto por arquitectos, diseñadores, comunicadores, publicistas, profesores de universidad, investigadores, escritores, artistas, músicos y profesionales de las artes plásticas, perteneciendo a la clase creativa todos aquellos para quienes la creatividad es un pilar fundamental en el trabajo y desarrollo laboral en cualquier sector económico.

Un segundo componente determina que, dicha clase creativa requiere un sitio de la ciudad o una ubicación, en donde se han de proporcionar mercados laborales con densidad creativa, que posibilite la gestión de un ecosistema que aproveche la creatividad humana y la transforme en valor económico. Tal es el caso del barrio El Prado, ya que este denota la configuración pertinente y necesaria del espacio público, desde sus espacios de permanencia, de movilidad peatonal y vehicular, creando entornos públicos que relacionan las funciones urbanas necesarias para articular 
las necesidades urbanas del barrio (Martínez, 2013) con el desarrollo de las actividades creativas, integrando a la población, y fomentando el encuentro y el diálogo ciudadano. Este es un espacio urbano potencial de desarrollo cultural que invita a su apropiación por parte de los ciudadanos y sus agremiaciones corporativas, artísticas y vecinales. En suma, es un espacio urbano que conlleva al redescubrimiento de la ciudad, de sus lugares, de su patrimonio e historia, logrando aportar identidad a la ciudadanía y al territorio en donde confluyen las actividades creativas y culturales.

Es importante resaltar que la administración pública nacional, y municipal, de la mano con las universidades y el sector privado, han aportado al desarrollo de las industrias creativas, gracias a iniciativas de clúster, Áreas de Desarrollo Naranja (ADN), Distritos Creativos y alianzas públicoprivadas, lo cual abre el tercer componente indispensable en la proyección del Museo Vivo El Prado, referido a las políticas culturales: Las políticas culturales se pueden decantar como políticas de desarrollo de ciudad o políticas de transformación urbana, debido a que la cultura es interdisciplinar y transdisciplinar, cuando de aspectos de desarrollo del territorio se refiere. Hoy, las ciudades requieren servicios administrativos, públicos y tecnológicos, sumado a que también necesitan acciones que estructuren las diferentes maneras de integración y cohesión social entre sus ciudadanos, y es precisamente en este punto en donde la cultura juega un estratégico papel, de manera que se establezcan lazos sociales en los procesos de vivir la ciudad bajo configuraciones caracterizadas del territorio, tal como el caso del Museo Vivo El Prado.

De acuerdo con Nicolás Barbieri, la cultura es un elemento muy estructurante e importante en la organización de la sociedad y en el desarrollo territorial:

"La cultura - en sus diferentes acepciones - ha adquirido un rol estratégico en la organización de la sociedad y en el desarrollo territorial que busca integrar una economía del conocimiento con la cohesión social, la gobernanza y la sostenibilidad. Las ideas y los valores asignados a la cultura han evolucionado hasta transformarla en un terreño elástico y omnipresente, un espacio des del cual se busca promover el desarrollo económico y social. Esta condición se ha acentuado en las últimas tres décadas a partir de fenómenos como la retracción del estado como garante del bienestar social, la desafección verso la representación democrática y la institucionalidad tradicional o la caducidad de las categorías habituales de identificación colectiva. Este proceso ha supuesto un conjunto de retos para las políticas culturales, que han intentado responder a los dilemas, frecuentemente irreconciliables, que este nuevo orden plantea" (Barbieri, 2011)

Las ADN (áreas de desarrollo naranja) basadas en la oferta cultural y creativa son espacios que operan como centros de ordenamiento territorial o decisiones administrativas de la entidad territorial, que tengan por objeto incentivar y fortalecer las actividades culturales y creativas previstas en el artículo 2 de la Ley 1834 de 2017.

Teniendo en cuenta lo anterior, se da el cuarto componente, siendo este el de las políticas culturales nacionales (economía naranja) las cuales ofrecen las herramientas y el marco de actuación 
normativo para obtener una gobernanza del Museo Vivo El Prado con la formación de un área de desarrollo naranja (ADN). Fomentar actividades de economía naranja es una de las metas que tiene el Gobierno de Colombia, y las plataformas que utiliza para gestionarlas se denominan las Áreas de Desarrollo Naranja (ADN).

Se entiende por Áreas de Desarrollo Naranja- ADN

"los espacios geográficos que sean delimitados y reconocidos a través de instrumentos de ordenamiento territorial, o decisiones administrativas de la ciudad o municipio, que tienen por objeto incentivar y fortalecer las actividades culturales y creativas previstas en el artículo 2 de la Ley 1834 de 2017. Las ADN basadas en la oferta cultural y creativa son espacios que operan como centros de actividad económica y creativa, contribuyen a la renovación urbana y al mejoramiento del área de ubicación, crean un ambiente propicio en el que confluyen iniciativas en estos campos, fortalecen el emprendimiento, el empleo basado en la creatividad, el turismo, la recuperación del patrimonio cultural construido, la conservación medioambiental, la transferencia de conocimientos, el sentido de pertenencia, la inclusión social y el acceso ciudadano al oferta cultural y creativa".(Ley 1955 de 2019, Plan Nacional de Desarrollo 2018 2022 "Pacto por Colombia, Pacto por la Equidad").

Así mismo, establece una articulación de los residentes originales del barrio El Prado con el desarrollo de la economía creativa y el consumo cultural, buscando el equilibrio socio económico y cultural, tanto para con sus vecinos como para la ciudad de Barranquilla. En este sentido, se refuerza la idea de que la cultura se convierte "cada vez más el negocio de las ciudades, la base de sus atracciones turísticas y su única ventaja competitiva" (Zukin,1995).

Finalmente, un distrito de innovación cultural y creativo que se gestiona y gobierna desde un área de desarrollo naranja, tal como se propone para el Museo Vivo El Prado, se configura como un sector de la ciudad de Barranquilla, donde la diversidad de expresiones patrimoniales y producción cultural, se consolidan como el insumo para la creación, la experimentación e innovación cultural sobre la transformación del propio territorio y sus dinámicas socio ciudadanas.

\section{CONCLUSIONES. EL MUSEO VIVO EL PRADO, UNA CUESTIÓN DE FUTURO.}

El patrimonio es una oportunidad para el desarrollo integral de las ciudades. El Barrio El Prado, lo es en Barranquilla. Su valor patrimonial radica no sólo desde su dimensión física, en la que resaltan los elementos de la arquitectura que tanto enaltecen y embellecen el territorio, sino también desde los otros patrimonios, los intangibles, aquellos que constituyen la identidad del lugar, a través de las dinámicas cotidianas de los ciudadanos. Esos patrimonios intangibles que hacen que un territorio sea vivo y que finalmente consolidarán la memoria y mantienen vivo cualquier territorio. Hoy esos otros patrimonios están en peligro de desaparecer, por ello, estamos 
llamados a reivindicar, regenerar, recuperar y devolverle la esencia a un barrio con una riqueza arquitectónica, urbanística, pero, sobre todo, desde, con y para su gran patrimonio VIVO.

Plantear la creación de un Museo Vivo, tiene diversas implicaciones en la contextualización de unas dinámicas urbanas existentes y con las que se pretende potencializar la productividad del espacio público. No se trata simplemente de poner en evidencia unas edificaciones que tienen un valor patrimonial per se. La configuración de un museo vivo implica la abstracción de unas características históricas que conservan un valor patrimonial de quienes habitan un territorio y actualizarlo a unas dinámicas socioculturales contemporáneas marcadas por una serie de complejidades de índole político, social, económico, tecnológico, cultural, etc. "Las tendencias en las que actualmente se enmarca el proceso urbano -donde las lógicas de la globalización, condicionadas, entre otros factores, por la consolidación de una nueva fase de acumulación territorial del capital, por realidades mediatizadas a través de sofisticadas tecnologías de la comunicación y por paradigmas culturales de impronta posmoderna estructurados alrededor de la dicotomía global-local han determinado que su sentido se redefina desde una noción de concentración demográfica y de urbanización, hacia la idea de estructuras socioespaciales dispersas y fragmentadas". (Uribe, M., 2019).

Es así como el 'Museo Vivo El Prado', se instituye como una iniciativa que muestra el patrimonio como una cuestión de futuro, rompiendo el paradigma de los museos tradicionales que se configuran con una edificación estática, lo que desde la dimensión de la gestión y control de la edificación le da una dimensión de alguna manera privativa. El Museo Vivo el Prado en cambio, se enmarca en una dimensión de lo público por su uso libre, pues todo el espacio urbano del barrio es el museo, y el confinamiento sólo está dado por el cielo, por el plano del suelo (pavimentos, asfaltos, etc.) y los límites administrativos del barrio.

Así mismo, el Museo Vivo El Prado es una reivindicación del valor que tiene el barrio en la estructura y la morfología de Barranquilla, una herencia de los otrora criterios urbanizadores del modelo de 'Ciudad Jardín' (Howard, 1902) que se expandía por el mundo a principios del siglo XX, especialmente en Latinoamérica, Europa y Estados Unidos. Ese modelo que, entre otras cosas, plantea casas grandes, con antesalas ajardinadas y monumentales, con ordenación y estructura que evocaba un paisaje verde, urbano, bastante respetuoso con el medioambiente, pero que se fue perdiendo poco a poco, y que gracias a la próxima expedición del Plan Especial de Manejo y Protección (PEMP), podrá ser recuperado y enaltecido, facilitando aún más el escenario expositivo del barrio.

En el barrio El Prado, visto como un Museo Vivo, y desde una perspectiva poética, el patrimonio cobra vida y las exposiciones ocurren a cielo abierto. El espacio público, adquiere una dimensión estructurante y de soporte de las "piezas museísticas". Todo aquello que integra los tres planos del espacio: plano vertical, plano horizontal y plano del aire (Remesar, A., \& Esparza, D., 2012), son parte esencial en el proceso de catalogación del Museo. Así, estas piezas en el espacio urbano, sumado al dinamismo, en el proceso de resignificación con la ciudadanía, los vecinos del barrio y los visitantes son las que darán sentido vivo al museo. Pero, además, como en cualquier otro museo del mundo, el de El Prado, podrá alojar exposiciones itinerantes y temporales provenientes de otros lugares y con enfoques que conjuguen la idea del Museo VIVO. Ejemplos como el de La araña «Maman» de la artista francesa, Louise Bourgeois expuesta en las 
inmediaciones del Guggenheim de Bilbao y cruzó fronteras a varias ciudades del mundo. O por ejemplo La escultura "Gran Elefant dret» del artista Mallorquín Miguel Barceló, instalada en el espacio público circundante del CaixaForum de Barcelona y de muchas otras ciudades de Europa, irrumpiendo no solo en el paisaje urbano, sino que de alguna manera activando el lugar. O intervenciones que activen los espacios públicos del barrio, a través de elementos que convoquen en concierto de varios actores.

La concepción y las dinámicas del Museo Vivo El Prado no serán una tarea exclusiva de los arquitectos o Urbanistas. La intervención del patrimonio debe ser una tarea conjunta interdisciplinaria que permita no sólo la restauración de un bien patrimonial, sino que su intervención permita una actualización y una utilidad vigente en las dinámicas sociales contemporáneas apreciadas desde la perspectiva de los diferentes campos del saber.

"Se vuelve necesario identificar, desde el debate académico, las distintas entradas teóricas del campo disciplinar de los estudios de la ciudad, con el objetivo de entender esta suerte de re-escalamiento conceptual de una condición urbana, incorporando además una lectura transversal de carácter multidisciplinario que más allá del hecho espacial per se, permita dar cuenta de la complejidad de esos procesos". (Beuf y Martínez, 2015).

Ese análisis del objeto patrimonial y su contextualización urbana permitirá identificar la "vocación" del inmueble y aprovechar su valor histórico para articularlo con una actividad contemporánea que garantice su permanencia en el corto, mediano y largo plazo, a partir de la definición de unas estrategias concretas de transformación en el tiempo.

El descubrir esa Vocación del inmueble implica la necesidad de realizar un diagnóstico inicial y recopilación de información, en la cual juega un papel muy importante no sólo la calidad de la información, sino la forma de organizarla, estructurarla y disponerla para los diferentes fines productivos del proyecto de museo. De una adecuada estructuración de la información dependerá el aprovechamiento y calidad de los resultados propuestos para el museo vivo, teniendo en cuenta que dicha información tendrá un carácter multidisciplinario y por ende multiplicidad de usos.

La recopilación, transformación y generación de nuevo conocimiento desde las diferentes disciplinas, permitirá desde lo académico, definir unas nuevas dinámicas que aporten a una nueva valoración social y una nueva apropiación tanto de quienes habitan el barrio como de aquellos que lo visitan. En esencia, es una puesta en conocimiento del valor patrimonial (material e inmaterial) que tiene el barrio para hacerlo propio en sus habitantes y dinamizarlo con actividades que le garanticen una vigencia futura.

El Museo Vivo El Prado reivindica la calle como lugar por excelencia de la sociabilidad y la interacción ciudadana. Invita a una manera interactiva de hacer ciudad, y esto quiere decir, vivir, experimentar y potenciar sus abigarradas dinámicas, que no requieren de una puesta escenográfica o del diseño de un guion museográfico convencional, porque son manifestaciones que surgen de manera espontánea en este gran espacio museal a cielo abierto, iniciativa que consolida el enfoque del Patrimonio como Cuestión de futuro, debido al potencial para su desarrollo y sostenibilidad socioeconómica y cultural, aprovechando las ventajas relativas y las dinámicas actuales, que seguramente también irán mutando con el tiempo. 
Es una fuente viva de información que se apoya en el valor histórico, potenciando su importancia en el presente, y proyectando el futuro, desde la visión del desarrollo. El museo imprime valor a la amalgama de material histórico, sumado a la amalgama de instancias, relaciones e intercambios que ahí suceden y que poco a poco, a lo largo de 100 años, han ido configurando un tejido social-cultural. También reivindica una forma de hacer ciudad, la cual escapa largamente de los parámetros institucionales (entiéndase desde la perspectiva del aparataje normativo, burocrático, político y académico) de la planificación urbana, ya que, como proceso histórico con sus infortunios y aciertos, podemos reconocer en él como resultado un desarrollo humano y un bienestar urbano admirable que hoy posicionan al barrio como un núcleo urbano atesorado por los Barranquilleros.

El Barrio El prado se convierte así en un nuevo distrito de oportunidades y manifestaciones culturales para Barranquilla. Una nueva propuesta urbana, que establece un sistema de imaginarios y representaciones en permanente crecimiento ya que es un escenario urbano, en donde el consumo de lo simbólico define la creación de un área de desarrollo naranja ADN, referido a los aspectos de la economía naranja (creativa) en Colombia, motivando la gestión de espacios definidos para las expresiones culturales. Por lo anterior, desde y para el barrio El Prado, se produce un distrito de innovación cultural y creativo puesto en escena desde la plataforma de las vivencias de sus residentes y del recorrido patrimonial y cultural que lo acompaña.

\section{Bibliografía}

ARANGO CARDINAL, S. (1993). Historia de la arquitectura en Colombia. Universidad Nacional de Colombia, Bogotá.

AUGÉ, MARC. (1992). Los no lugares. Espacios del anonimato. Una antropología de la sobremodernidad. Barcelona, Gedisa.

BARBIERI, N. (2011). "Polítiques culturals com a polítiques urbanes? Una mirada sobre el valor públic i els límits de la cultura". Eines per a l'esquerra nacional, (14), 27-36.

BARTHES, R. (1971) Semiología y urbanismo. La aventura semiológica. Paidós. Madrid, 1992. “

BAYONA, J. F., \& LLANOS, R. (Eds.). (2016). Memorias de El Prado: arquitectura y urbanismo 1920-1960. Universidad del Norte.

BEUF, A., \& MARTÍNEZ, M. (Eds.). (2015). Colombia: Centralidades históricas en transformación. Instituto Distrital de Patrimonio Cultural.

BOSCHERINI, F. P. L, comp. (2000) Territorio, conocimiento y competitividad de las empresas. El rol de las instituciones en el espacio global, Buenos Aires, UNGS y Editorial Miño y Dávila.

BRANDÃO, P. (2011). Imagen de la ciudad, Las estrategias de identidad y comunicación. Edicions Universitat Barcelona.

CABALLERO, J. (2000). Barranquilla y la modernidad: Un ejercicio histórico. Bogotá, Facultad de Artes, Universidad Nacional de Colombia.

CABRERA SÁNCHEZ, I. (2013). Los planes parciales de renovación urbana en Bogotá (2000-2012): identificación de obstáculos y planteamiento de estrategias de gestión (Master's thesis, Universitat Politècnica de Catalunya).

CALVO, S. C. (2015). Los museos sin edificio. Estudio de caso práctico. El museo riojano de arte contemporáneo-murac de 2006 a 2013 (Doctoral dissertation, Universidad Miguel Hernández de Elche).

CORDOBA, G. G. D. P. (2017). “EL Patrimonio Arquitectónico como Espacio de Comunicación Interdisciplinar." MÓDULO ARQUITECTURA CUC, 19, 21-56.

COROMINAS, J., \& PASCUAL, J. A. (1980). Diccionario crítico etimológico castellano e hispánico. Gredos.

COWAN, R., \& ROGERS, L. (2005). The dictionary of urbanism (Vol. 67). Tisbury: Streetwise press. 
DARDEL-CORONADO, M. (2019). "Espacio y paisaje como criterios curatoriales en el Museo a Cielo Abierto de Valparaíso". Arte, Individuo y Sociedad, 31(3), 557.

DEROSAS CONTRERAS, D., \& GARCÍA DE LA VEGA, A. (2019). "Museo a cielo abierto en San Miguel como experiencia de paisaje musealizado". Diferents. Revista de museus, 2019, número 4.

DUPUY, G. (1998). El urbanismo de las redes. Teorías y métodos. Barcelona: Oikos-Tau.

FLORIDA, R. (2010). La clase creativa: la transformación de la cultura del trabajo y el ocio en el siglo XXI. Grupo Planeta (GBS).

FOWLE, K. (2007). "Who cares? Understanding the role of the curator today. Cautionary tales": Critical curating, 2635.

FROST-KUMPF, H. A. (1998). Cultural districts: The arts as a strategy for revitalizing our cities. Americans for the Arts.

GARCÍA, DIAZ MADELEINE. (7 de octubre de 2019) "La reivindicación de memoria histórica del barrio San Miguel, en Bucaramanga". Periódico 15. Recuperado de https://www.periodico15.com/la-reivindicacion-de-memoria-historicadel-barrio-san-miguel-en-bucaramanga/

GARCÍA, M. R. C. (2010). "Conceptualización del espacio arquitectónico a través de la historia". Modulo Arquitectura CUC, 9, 87-104.

GRENNE, M., \& MORA, R., 2011. "El proyecto urbano desde una visión sistémica." En M. Grenne, L. Valenzuela y J. Rosas. Proyecto Urbano, Santiago: Ediciones ARQ.

GUILLOT, MARIA FERNANDA (2020, 02 de febrero) Chacarita: cómo el barrio funebrero se volvió cool. Diario El Clarín. Recuperado de https://www.clarin.com/viva/chacarita-barrio-funebrero-volvio-cool 0 AcRcNPq8.html

HARVEY, D. (2007). Espacios del capital. Hacia una geografía crítica. Madrid: Akal.

HOWARD, EBENEZER. (1902). Garden Cities of Tomorrow. S. Sonnenschein \& Co., Ltd. http://www.sacred-texts.com/ utopia/gcot/index.htm

ICOM, Consejo Internacional De Museos. (2007). Estatutos ICOM. Modificados y adoptados por la asamblea general extraordinaria, el 24 de agosto de 2007. París: ICOM

IDPC, INSTITUTO DISTRITAL DE PATRIMONIO CULTURAL (2020). Recuperado de: https://idpc.gov.co/elementskitcontent/dynamic-content-widget-8cb8068-2/

LAZZERETTI, L. (2008). “El distrito cultural”. Mediterráneo económico, (13), 327-351.

LEFEBVRE, H. (2013). La producción del espacio. Madrid: Capitán Swing.

Ley 1955 de 2019. Plan Nacional de Desarrollo 2018- 2022 "Pacto por Colombia, Pacto por la Equidad". Congreso de la República de Colombia, Bogotá D.C. Colombia, 2018.

LÓPEZ-MARTíNEZ, J. (2017). Antecedentes arquitectónicos patrimoniales del departamento del Atlántico. https://doi. org/10.17981/mod. arq. cuc. 22.1. 2019.01.

LYNCH, K. (1960). La imagen de la ciudad (EL Revol, Trad.). Barcelona: Gustavo Gili.

MARTÍNEZ PALACIOS, E. (2013). El modelo Barcelona de espacio público y diseño urbano. El espacio público asociado a la infraestructura de movilidad rápida y rodada de Barcelona. Universitat de Barcelona http://hdl.handle. net/2445/56349

MEDINA, E. H., SANDOVAL, M. D. P. M., \& PRIETO, L. F. M. (2012). Propuesta para postular la Localidad de Chapinero como distrito cultural y creativo de Bogotá. Nodo: Arquitectura. Ciudad. Medio Ambiente, 6(12), 19-32.

MÈLICH, J. C. (2012). Filosofía de la finitud. Herder Editorial.

MEYER, D. \& YIDI, E. (2015). Barrio El Prado, un viaje hacia el pasado. Bogotá: Panamericana formas e impresos S.A.S.

MORALO MÁRQUEZ, A., \& TRESSERRAS, J. M. (2017). El Distrito Cultural de L'Hospitalet. La transformación del espacio público a partir de la cultura.

MOUTINHO, M. C. (2010). "Los ecomuseos para La armonía socia"I. Notícias Del ICOM, 63(1), 9.

OSSANDÓN, FERNANDO (octubre de 2017). Usos comunitarios y alternativos de los espacios públicos. II Encuentro internacional de gestores culturales: saberes y haceres de la gestión cultural. Fundación Visión Cultural. Congreso llevado a cabo en Santa Cruz de la Sierra, Bolivia. 
OSSANDÓN, FERNANDO; JARA, VICTORIA; POBLETE, FERNANDA (2017). Museo a Cielo Abierto en San Miguel: una mirada artística y comunitaria del muralismo en espacios públicos. Discusión bibliográfica. Proyecto presentado al Fondart Nacional 2018 / Artes Visuales / Investigación- Artes Visuales.

PADILLA LLANO, S. E. (2015). Producción de espacio público [X] Participación ciudadana. El proyecto de espacio público resultado de procesos de participación ciudadana. . Universitat de Barcelona http://hdl.handle.net/10803/309288

PÉRGOLIS, J. C. (2011). Ciudad republicana y deseo de modernidad. Módulo Arquitectura CUC, 10, 225-236.

PINTO, A. J., \& REMESAR, A. B. (2015). "Urban cohesion: A public space network assessment". On the W@ terfront. Public Art. Urban Design. Civic Participation. Urban Regeneration, 39(2), 7-25.

POSSO, L., (2013). Getsemaní: de barrio periférico a núcleo de la escena cultural contemporánea. Visitas al Patio. REMESAR, A. (2011). "Public Art, strategies for the regeneration of public space". On the w@terfront, (17), 3-27.

REMESAR, A.. (2016). "Arte público. Retos y oportunidades (II). La consolidación de los lenguajes". On the Waterfront., 2016, vol. 41, num. 2, p. 7-59.

REMESAR, A; ESPARZA LOZANO, D. (2012). Imágenes congeladas. La imagen del centro histórico. En SINUA. Simposio Internacional de Urbanismo y Arquitectura. 16 Convención Científica de Ingeniería y Arquiectura. CUJAE.

REYES SCHADE, E. (2017). El Espacio Público como Interfaz. Tranvía y Metro en Barcelona.. Universitat de Barcelona

REYES SCHADE, E (2018). "La interfaz urbana. Una aproximación”. On the W@ terfront. Public Art. Urban Design. Civic Participation. Urban Regeneration, 60(7), 3-40.

RICART, N. \& REMESAR, A. (2013). “Reflexiones sobre el espacio público.” On the W@ terfront, (25), 5-35.

RIUS ULLDEMOLINS, POSSO JIMENEZ LADYS. (2016, mayo) “Cultura, transformación urbana y empoderamiento ciudadano frente a la gentrificación. Comparación entre el caso de Getsemaní (Cartagena de Indias) y el Raval (Barcelona)". Revista Eure, Vol 42, N 126. Recuperado de http://www.eure.cl/index.php/eure/article/view/1718/881 ROSSI, A. (1999). La Arquitectura de la ciudad. Barcelona [etc.]: Gustavo Gili.

SIMÓ, M. (2013). "El concepto de regeneración urbana sostenible: una aplicación a la llei de barris". En AA.VV. XI Congreso Español de Sociología. Crisis y Cambio. Recuperado de http://www.fes-sociologia.com/el-concepto-deregeneracin-urbana-sostenible-una-aplicacin-a-la-llei-de-barris/congress-papers/1669/

SMITH, T., \& FOWLE, K. (2012). Thinking contemporary curating. Independent Curators International.

URIBE GONZÁLEZ, M (2019). Otra Oportunidad para el patrimonio Construido. Patrimonio Renovado, Instituto Distrital de Patrimonio Cultural, Alcaldía de Bogotá.

URQUIZO, W. L. (2006). "Barrio y ciudad Historiografía urbanística y la cuestión del dominio de referencia. El caso de Lima”. Revista Bitácora Urbano Territorial, 10(1), 82-105.

VERGARA, R. A., \& VIDAL ORTEGA, A. (2011). Barrio el Prado. Barranquilla. Universidad del Norte.

WOLF AMAYA, G. M. (2016). La incidencia del barrio burgues en la configuración de la ciudad latinoamericana.

ZARLENGA, M., \& MARCÚS, J. (2014). "La cultura como estrategia de transformación urbana. Un análisis crítico de las ciudades de Barcelona y Buenos Aires". en M. MARGULIS, ET AL. Intervenir en la cultura: más allá de las políticas culturales. Buenos Aires: Biblos.

ZUKIN, S. (1995). The cultures of cities . Oxford: Blackwell. 
